\title{
EL EFECTO DIRECTO DEL DERECHO INTERNACIONAL EN EL DERECHO CHILENO*
}

\author{
Ximena Fuentes Torrijo y Diego Pérez Farías**
}

RESUMEN: En este artículo se esboza una teoría sobre la autoejecutabilidad de los tratados en Chile que toma como punto de partida la distribución de competencias que realiza la Constitución respecto de la creación de normas. Se subraya la distorsión que se genera al darle autoejecutabilidad a tratados que intentan regular materias propias de ley, siendo que la Constitución Política ha establecido que la ley debe ser el producto de una deliberación democrática que se lleva a cabo en el Congreso. Por lo tanto, los tratados que intentan regular materias propias de ley no deberían ser autoejecutables. Sin embargo, como en Chile la práctica constitucional otorga autoejecutabilidad a los tratados internacionales, este artículo asume esta realidad y discute entonces la posibilidad de restringir la autoejecutabilidad de los tratados en base a una serie de criterios que deberían tomarse en cuenta por los operadores jurídicos chilenos al resolver sobre la aplicación directa de tratados internacionales.

PALABRAS CLAVE: Autoejecutabilidad; efecto directo; tratados; derechos humanos; distribución de competencias

Fecha de recepción: 12 de febrero de 2018.

Fecha de aceptación: 20 de noviembre de 2018.

Este artículo es parte del Proyecto Fondecyt 1070185 "La aplicación del derecho internacional en el sistema jurídico chileno".

** Ximena Fuentes, D.Phil (Oxon), Profesora de Derecho Internacional en la Universidad de Chile (Chile); Diego Pérez, Licenciado en Ciencias Jurídicas y Sociales de la Universidad de Chile, ayudante de Derecho Internacional en la Universidad de Chile (Chile).

Emails: ximena.fuentes@gmail.com y dperezfarias@gmail.com

El presente artículo se inserta en el marco conceptual sobre la relación entre el derecho internacional y el derecho interno desarrollado por Ximena Fuentes en diversos artículos: Fuentes, Ximena (2008) "International Law and Domestic Law: Definitely an Odd Couple", Revista Jurídica de la Universidad de Puerto Rico, vol. 77, pp. 483-505; Fuentes, Ximena (2014) "La jerarquía y el efecto directo del derecho internacional en el sistema jurídico chileno. En: Atria, Fernando et al. (eds.) Una Vida en la Universidad de Chile: celebrando al profesor Antonio Bascuñán Valdés. Santiago: Thomson Reuters, pp. 583-618; Fuentes, Ximena (2015) "Una Nueva Constitución para Chile y el Diseńo de un Esquema de Incorporación del Derecho Internacional al Sistema Jurídico Chileno". En: CHiA, Eduardo; QueZADA, Flavio (eds.) Propuestas para una Nueva Constitución. Santiago: Instituto Igualdad, Fundación Friedrich Ebert y Facultad de Derecho de la Universidad de Chile, pp. 171-193. Forma parte del desarrollo de este marco conceptual la memoria de pregrado de Diego Pérez guiada por Ximena Fuentes. Pérez, Diego (2015) "El efecto directo de los tratados internacionales en el derecho chileno", que analiza extensamente el efecto directo de los tratados internacionales tanto en derecho comparado como en el derecho chileno. 


\section{THE DIRECT EFFECT OF INTERNATIONAL LAW IN THE CHILEAN LEGAL SYSTEM}

ABSTRACT: This Article attempts to articulate a theory about the self-executing character of treaties in Chile, taking as a starting point the allocation of competences effected by the Constitution. The paper highlights the distortion that results when treaties are given direct effect in relation to matters that should be regulated by law, thus contradicting the Constitution that provides that legislation should be the product of a democratic deliberative process undertaken by Congress. Therefore, treaties that attempt to regulate matters that pertain to law, should not be self-executing. Insofar as in Chile constitutional practice ascribes selfexecuting character to treaties in general, this Article takes that reality as a fact and, on that basis, discusses about the possibilities of applying a restrictive theory of direct effect that would rely on the operation of certain relevant criteria that should be taken into account by state organs when they decide about the self-executing character of international treaties.

KEY WORDS: Self-executing; direct effect; treaties; human rights, allocation of competences

Sumario: Introducción. 1) La Distinción entre Tratados Autoejecutables y No Autoejecutables. 2) "El Futuro del Derecho Internacional Es Doméstico". 3) Chile: Falta de Reglas y Falta de Doctrina. 4) Un Esbozo para una Teoría sobre la Autoejecutablidad de los Tratados en Chile. 5) Los Criterios Relevantes para determinar la Autoejecutabilidad de los Tratados. (5.1.) El texto del tratado. (5.2.) Regimenes jurídicos que no se pueden reemplazar por los jueces. (5.3.) La tipificación de delitos. (5.4.) Tratados que no establecen derechos para los particulares. (5.5.) El otorgamiento de facultades a órganos estatales. Conclusiones.

\section{INTRODUCCIÓN}

El derecho internacional forma parte del ordenamiento jurídico nacional. Ya nadie puede poner en duda esta afirmación desde el momento en que los jueces chilenos suelen citar normas internacionales como la base normativa de sus decisiones. Así, por ejemplo, se puede afirmar que el Decreto Ley de Amnistía de 1978 ha sido tácitamente derogado por aplicación de las Convenciones de Ginebra de 1949 en una interpretación 
realizada por los tribunales de justicia ${ }^{1}$. Vía recurso de protección los jueces han ordenado la paralización de ciertos proyectos productivos porque, en su opinión, su realización contradiría las reglas de la Convención de Washington sobre la Protección de la Flora, la Fauna y la Belleza Escénica de $A_{\text {mérica }}{ }^{2}$. Por su parte, la Contraloría General de la República ha sostenido que el control de legalidad incluye asegurarse que los actos de la administración del Estado se conformen con las normas de tratados internacionales que resulten aplicables ${ }^{3}$. Es claro, entonces, que los tratados internacionales están produciendo cada vez un mayor impacto en el ordenamiento jurídico chileno y que lo que permite este creciente impacto es el efecto directo o autoejecutabilidad del derecho internacional en el derecho interno.

El efecto directo de los tratados consiste en que estos adquieren tal fuerza normativa dentro del ordenamiento jurídico nacional que pueden ser aplicados por los operadores jurídicos respectivos sin necesidad de la dictación de legislación nacional complementaria. De esta manera, un tratado que tiene efecto directo en Chile puede ser aplicado por un juez nacional para solucionar los litigios de que conoce. Del mismo modo, un órgano como la Contraloría General de la República podría efectuar el control de legalidad de los actos de la administración en función de la compatibilidad de esos actos con un tratado vigente en Chile. Como se puede apreciar, en principio, se puede hablar de efecto directo respecto de la operación de tratados por diferentes órganos del Estado. Sin embargo, en la literatura comparada el uso de los conceptos de efecto directo o autoejecutabilidad se limita a la aplicación del derecho internacional por los tribunales de justicia internos ${ }^{4}$.

1 Ver los comentarios de Ximena Fuentes a diversas sentencias de la Corte Suprema sobre aplicación de los Convenios de Ginebra de 1949 y su interacción con el DL de Amnistía de 1978 en: Fuentes, Ximena (2004) "Aplicación de Tratados Internacionales en el Derecho Interno", Revista de Derecho de la Universidad Adolfo Ibáñez, vol.1 pp. 717-735, pp. 717-722; Fuentes, Ximena (2005) "Aplicación de Tratados Internacionales en el Derecho Interno", Revista de Derecho de la Universidad Adolfo Ibáñez, vol. 2, pp. 1193-1216, pp. 1193-1200; Fuentes, Ximena (2013) "Derecho Internacional Público. Convenios de Ginebra (1949)", Revista de Derecho de la Universidad Adolfo Ibánez, vol. 3, pp. 529-545, pp. 529-542.

2 La jurisprudencia relevante en esta materia se analiza más adelante.

3 Contraloría General de la República. 26 de diciembre de 2006. Dictamen No 61817. Disponible en: https://www.contraloria.cl/pdfbuscador/dictamenes/061817N06/ html?print=true [fecha de visita: 20 de febrero de 2018].

$4 \quad$ VÁsquez, Carlos Manuel (1995) "The Four Doctrines of Self-Executing Treaties". American Journal of International Law, vol. 89, pp. 695-723, p. 695. Ver también, NollKaemper, André (2004) "The Direct Effect of Public International Law". En: Prinssen, Joland y Schrauwen, Annette (Eds.) Direct Effect Rethinking a Classic of EC Legal Doctrine. Groningen: Europa Law Publishing, pp. 157-180, p. 159. 
En este artículo se discutirá sobre los problemas que plantea la aplicación directa de los tratados por los operadores jurídicos en el esquema de distribución de competencias que establece la Constitución para el sistema jurídico chileno. Un primer problema deriva de la combinación de dos características que se otorga, en Chile, a los tratados: la supralegalidad y la autoejecutabilidad. Por un lado, se ha tendido a considerar que los tratados tienen una jerarquía supralegal, en el sentido que un tratado que se incorpora al sistema jurídico chileno no puede ser modificado por una ley posterior ${ }^{5}$. Y, por otro, se ha considerado que los tratados internacionales son, por regla general, directamente aplicables por los tribunales nacionales, sin la necesidad de legislación o medidas administrativas que los implementen. De esta forma, un tratado que es superior a la ley y autoejecutable, otorga un gran poder a los jueces ya que su particular interpretación y aplicación de estos queda de alguna manera inmune al Poder Legislativo. En otras palabras, gracias al efecto directo del derecho internacional, los jueces adquieren el poder de dar por derogadas tácitamente leyes por ser supuestamente contrarias al derecho internacional y, gracias a la teoría de la supralegalidad, el Poder Legislativo queda impedido de evitar esta consecuencia porque, aun cuando dictara una ley que intentara mantener la vigencia de las leyes frente a los tratados no podría, porque los jueces responderían que el tratado tiene una jerarquía supralegal y no puede ser modificado por la ley posterior ${ }^{6}$.

Esto nos lleva al segundo problema relacionado con la autoejecutabilidad de los tratados. Después de constatar que la combinación entre supralegalidad y autoejecutabilidad permite que los tratados dejen sin efecto las leyes nacionales sin vuelta atrás, la pregunta que debe formularse se refiere a la legitimidad democrática de un efecto normativo tan robusto. Los tratados no son normas deliberadas en el Congreso. Se trata de normas negociadas por el Poder Ejecutivo con otros Estados, ya sea en conferencias internacionales, o en negociaciones a nivel bilateral o multilateral ${ }^{7}$. El Poder Ejecutivo ejerce en estas negociaciones el poder que le otorga la Constitución de conducir las relaciones internacionales. El Congreso, luego, no podrá cambiar el texto del tratado que ya ha sido nego-

Para mayor detalle, véase Fuentes (2014) 594-604.

El Tribunal Constitucional ha seńalado que si bien los tratados tienen jerarquía de precepto legal una ley posterior no los puede derogar. Tribunal Constitucional, 25 de agosto 2009. Rol 1288 "Control de Constitucionalidad del proyecto de Ley que modifica la Ley 17.997, Orgánica Constitucional del Tribunal Constitucional”. Disponible en: https://www. tribunalconstitucional.cl/descargar_expediente2.php?id=7850 [fecha de visita: 20 de febrero de 2018] considerando quincuagésimosexto

7 Sobre la objeción del déficit democrático del derecho internacional, véase Fuentes (2008) 497-500, Fuentes (2015) y Pérez (2015) 13-15. 
ciado por el ejecutivo y se limitará a aprobar o rechazar el tratado antes de que pueda ser ratificado. Sin embargo, la autoejecutabilidad permitirá que el tratado tenga efectos normativos internos, equivalentes a los de una ley, a pesar de que no es el producto del poder de deliberación democrática entregado al Congreso.

Nos concentraremos en la autoejecutabilidad de los tratados ante los tribunales de justicia chilenos, y no revisaremos el tema de la costumbre internacional, porque el objetivo no es agotar el análisis de esta materia, sino que iniciar el debate y promover más estudios sobre el tema de la autoejecutabilidad del derecho internacional en Chile.

\section{1) La Distinción entre Tratados Autoejecutables y No Autoejecutables}

Legitimacy considerations support conceiving of direct effect and consistent interpretation as issues to be decided on the basis of domestic constitutional law. The positioning of a domestic legal order within the wider world necessarily affects fundamental issues such as democracy, self-determination, and the self-understanding of the citizenry ${ }^{8}$.

En Estados Unidos han sido los tribunales de justicia quienes han tratado de resolver esta cuestión mediante sus decisiones judiciales, creando en el curso del tiempo una doctrina sobre la autoejecutabilidad. En Inglaterra, la respuesta ha sido diferente y aparentemente más simple al haberse establecido el principio de Supremacía Parlamentaria, de manera que ningún tratado puede ingresar directamente al sistema jurídico británico 9 . Lo que sucede en Chile lo revisaremos en los capítulos posteriores; antes, es necesario analizar por qué la autoejecutabilidad ha encontrado una gran acogida en Latinoamérica.

8 Von Bogdandy, Armin (2008) "Pluralism, direct effect and the ultimate to say: on the relationship between international and domestic law". International Journal of Constitutional Law, Vol. 6, Nos. 3-4, p. 403. Véase Pérez (2015) pp. 15-29.

$9 \quad$ En palabras de la House of Lords, "Treaties, as it is sometimes expressed, are not self-executing. Quite simply, a treaty is not part of English law unless and until it has been incorporated into the law by legislation". Citado en SHAw, Malcolm N. (2008) International Law. 6th Edition. Cambridge: Cambridge University Press, pp. 1542, pp. 148-157, p. 150. Véase también, PÉrez (2015) 33-36. 


\section{2) “El Futuro del Derecho Internacional es Doméstico"}

Este es el sugerente título de un artículo de William Burke-White y Anne-Marie Slaughter, en que argumentan que la eficacia del derecho internacional depende finalmente de su capacidad para influir en la política interna de los Estados. En este contexto, señalan que las reglas y las instituciones internacionales, si se diseñan bien, pueden contribuir a través de los actores políticos y jurídicos locales al cumplimiento de las obligaciones internacionales ${ }^{10}$. Slaughter ya en 1995 había subrayado las bondades del empleo de los tribunales domésticos para lograr la mayor eficacia del derecho internacional al decir que el derecho internacional funciona mejor cuando puede tomar prestadas la legitimidad y las facultades coercitivas de los tribunales domésticos ${ }^{11}$.

No es que se trate de un descubrimiento nuevo. De hecho, desde el momento en que se establecieron delitos internacionales como la piratería, y en la medida que no existían tribunales penales internacionales, estuvo claro que la condena penal para los delitos transnacionales debía provenir de un tribunal nacional ${ }^{12}$. Esta fue una primera constatación de la utilidad de la cooperación entre el derecho internacional y el derecho nacional para dar mayor efectividad a las obligaciones internacionales.

Esa relación de cooperación se hizo absolutamente necesaria después de la Segunda Guerra Mundial con el surgimiento de los tratados de derechos humanos que buscan formas eficaces para obtener resarcimiento frente a las violaciones de derechos humanos ${ }^{13}$.

La posibilidad de usar los tribunales nacionales para hacer respetar los derechos humanos provee un mecanismo más eficiente que recurrir a tribunales u organismos internacionales de supervisión. Así lo reconocen expresamente varios autores que han propiciado el uso de los tribunales nacionales para dar protección a estos derechos. Conforti y Francioni, por ejemplo, afirmaban que, a pesar de la existencia de comités y tribunales internacionales de derechos humanos, la cooperación de órganos inter-

10 Slaughter, Anne-Marie; Burke-White, William (2006) "The Future of International Law is Domestic". Harvard International Law Journal, vol. 47, No 2, pp. 327-352, 333.

11 Slaughter, Anne-Marie (1995) "Review of Regime Theory and International Relations, Volker Rittberger and Peter Mayer”. American Journal of International Law, vol. 89 No 2, pp. 454-456: "international law works best when it can borrow the legitimacy of domestic law and the coercive powers of domestic courts".

12 O'Connell, Mary-Ellen (2008) The Power and Purpose of International Law. Oxford: Oxford University Press, pp. 408, p. 333. Ya en el siglo XVI Gentili escribía que la piratería podía ser considerada como crimen por cualquier soberano, ya fuera cometida en alta mar o incluso en otros territorios: Rubin, Alfred (1988) The Law of Piracy. Rhodes Island: Naval War College Press, p. 25.

13 Para mayor detalle, véase Fuentes (2014) 585-592. 
nos, en particular de los tribunales nacionales, era fundamental para que los derechos humanos fueran realmente eficaces ${ }^{14}$. Finalmente, fueron los propios tribunales internacionales y órganos internacionales de supervisión, los que decidieron tomar acciones positivas para propiciar que los tribunales nacionales intervengan en la protección de los derechos humanos contenidos en tratados internacionales, aun cuando en el derecho internacional general no existe una obligación de otorgar efecto directo a los tratados.

Por ejemplo, el Comité de Derechos Humanos -órgano de supervisión del Pacto Internacional de Derechos Civiles y Políticos (PIDCP) - fue evolucionando en su manera de enfrentar la pregunta sobre la obligación de los Estados de incorporar el Pacto en su derecho interno y darle efecto directo. Ante el Comité, en 1981, surgió la pregunta sobre la autoejecutabilidad de los derechos contenidos en el Pacto y sobre la correcta interpretación del artículo 2(2), que obliga a los Estados a dictar las normas necesarias para implementar los derechos contenidos en el convenio ${ }^{15}$. La pregunta se refería a si este artículo se podía leer en el sentido de que el Pacto no era directamente aplicable en los sistemas jurídicos internos. En su Observación General relativa a la Aplicación del Pacto a Nivel Nacional, el Comité señaló que, la manera en que un Estado decidía implementar las obligaciones del pacto dependía de su propio sistema jurídico ${ }^{16}$.

De alguna manera el artículo 2(2) reconoce que el PIDCP no es necesariamente autoejecutable en los ordenamientos jurídicos de los Estados Parte porque los llama expresamente a dictar la legislación necesaria para su implementación ${ }^{17}$. Pareciera ser que la interpretación correcta es que el Pacto no obliga a los Estados a otorgar efecto directo al Pacto, pero que tampoco lo excluye. De hecho, durante la negociación del Pacto, Estados

14 Conforti, Benedetto; Francioni, Francesco (1997) Enforcing International Human Rights in Domestic Courts. The Hague: Martinus Nijhoff, pp. 466, p. 3.

15 El artículo 2(2) del Pacto seńala: "Cada Estado Parte se compromete a adoptar, con arreglo a sus procedimientos constitucionales y a las disposiciones del presente Pacto, las medidas oportunas para dictar las disposiciones legislativas o de otro carácter que fueren necesarias para hacer efectivos los derechos reconocidos en el presente Pacto y que no estuvieren ya garantizados por disposiciones legislativas o de otro carácter. [...]"

16 Comité de Derechos Humanos, Observación General No. 3 (1981), "Aplicación del Pacto a Nivel Nacional (artículo 2)". Disponible en: http://ccprcentre.org/page/view/general_comments/27821 [f echa de visita: 20 de febrero de 2018]

17 En este sentido, ver Staberock, Gerald (2011) "Human Rights, Domestic Implementation”. En: Wolfrum, Rüdiger (Ed.), Max Planck Encyclopedia of Public International Law. Disponible en: http://opil.ouplaw.com/view/10.1093/law:epil/9780199231690/law9780199231690-e1734 [fecha: de visita: 28 de octubre de 2018], pfo. 14. 
Unidos propuso que se dijera explícitamente que el Pacto no era autoejecutable $^{18}$ y la propuesta fue rechazada ${ }^{19}$.

Posteriormente, en 1993, en Araujo-Jongen v. The Netherlands, el Comité fue aún más explícito en señalar que existen varios mecanismos para incorporar el Pacto en los ordenamientos jurídicos de los Estados y que la pregunta sobre el eventual efecto directo del Pacto se encontraba fuera de la competencia del Comité20. Sin embargo, alrededor de 1996 en adelante el Comité comienza a ser crítico respecto de aquellos Estados que no incorporan el Pacto en sus ordenamientos jurídicos internos y que no permiten su invocación directa ante sus tribunales internos ${ }^{21}$. No obstante esto, en 2004, el Comité vuelve a reconocer que el artículo 2 no exige que el Pacto sea directamente aplicable en los tribunales nacionales $^{22}$.

Por su parte, la Corte Interamericana de Derechos Humanos ha llegado más lejos en cuanto a abogar por la aplicación directa de la Convención Americana sobre Derechos Humanos en el ordenamiento jurídico de cada uno de los Estados Parte ${ }^{23}$. En efecto, esta Corte ha llegado a elaborar la controvertida tesis del control de convencionalidad, que consiste en la exigencia para los tribunales de cada Estado de verificar la compatibilidad de normas de derecho interno con la Convención Americana, la jurisprudencia de la Corte Interamericana y los demás tratados interamericanos de los cuales el Estado sea parte ${ }^{24}$, desplazando a la legislación

18 Doc. E/CN.4/224.

19 Como concluye Anja Seibert-Forth: "The drafters who rejected the United States proposal left the question whether the Covenant can be applicable as part of domestic law to the State parties. A direct application by courts of States parties was deemed to be possible. However, a direct application as a matter of international law, that is by virtue of the Covenant itself, was not intended." Seibert-Fohr, Anja (2001) "Domestic Implementation of the Internacional Covenant on Civil and Political Rights Pursuant to its Article 2 para.2" Max Plank Yearbook of United Nations Law, vol. 5, pp. 399-472, 420. Comité de Derechos Humanos, Comm. No. 418/1990 (1993), párrafo 7.5. Disponible en: http://hrlibrary.umn.edu/undocs/html/vws418.htm [fecha de visita: 20 de febrero de 2018]

21 Para una reseńa de los casos en que el Comité ha criticado a diversos países por no dar efecto directo al Pacto de Derechos Civiles y Políticos ver: Seibert-Fohr (2001) 434-437.

Comité de Derechos Humanos, Observación General No. 31 (2004), "Sobre la Naturaleza de la Obligación Jurídica General Impuesta a los Estados Parte en el Pacto”. En dicha observación se lee: "El artículo 2 (...) no exige que el Pacto sea directamente aplicable en los tribunales, mediante la incorporación del Pacto al derecho nacional. El Comité opina, sin embargo, que las garantías del Pacto pueden recibir una mayor protección en los Estados en los que automáticamente o por medio de una incorporación concreta pasa a formar parte del ordenamiento jurídico interno."

23 Véase Fuentes (2008) 485-491.

24 Corte Interamericana de Derechos Humanos, Cuadernillo de Jurisprudencia de la Corte Interamericana de Derechos Humanos $N^{\circ} 7$, p. 6. 
nacional si fuera necesario ${ }^{25}$. En síntesis, el control de convencionalidad exige que los tribunales nacionales consideren la Convención Americana como un tratado autoejecutable.

El camino hacia el control de convencionalidad comenzó tímidamente. En 1986, la Corte Interamericana sostuvo que la pregunta sobre el carácter autoejecutable de la Convención no caía dentro de sus competencias ya que se trataba de una pregunta a ser respondida por el derecho de cada país. En esa época Costa Rica había solicitado una opinión consultiva a la Corte en la que preguntaba si por el hecho de que la Convención Americana se encontraba incorporada al derecho costarricense podía entenderse que el derecho a réplica establecido en el artículo 14 de la Convención pasaba a operar directamente en Costa Rica sin necesidad de legislación adicional. En particular, la pregunta sometida a la opinión de la Corte fue la siguiente:

1.- ¿Debe considerarse que el derecho consagrado en el articulo 14 de la Convención Americana sobre Derechos Humanos está ya garantizado en su libre y pleno ejercicio a todas las personas que se encuentran bajo la jurisdicción del Estado costarricense, según se desprende de las obligaciones que para nuestro pais contiene el artículo $1^{\circ}$ de dicha Convención?

Como se puede apreciar, la pregunta se refería claramente al efecto de la Convención en el ordenamiento jurídico costarricense. Para algunos jueces, la Corte debió haberse declarado incompetente para conocer una pregunta sobre el derecho interno de Costa Rica (voto disidente de Nikken y Nieto Navia). Sin embargo, la Corte prefirió dar una lectura tal a esta pregunta que le permitiera ejercer su jurisdicción consultiva. Para esto la Corte señaló que la pregunta admitía dos interpretaciones: una relativa al derecho interno y la otra relativa al derecho internacional ${ }^{26}$. La Corte señaló que no podía pronunciarse sobre el aspecto relativo a la incorporación de la Convención en Costa Rica y que solo se pronunciaría sobre el aspecto internacional relativo a la interpretación del artículo 14.1 en relación con el 1.1. Es así como la Corte interpretó, lo que es obvio, que Costa Rica estaba obligada a respetar el derecho de rectificación o

\footnotetext{
25 Corte Interamericana de Derechos Humanos. Sentencia de 26 de septiembre de 2006. "Almonacid Arellano y otros vs. Chile". Disponible en: http://www.corteidh.or.cr/docs/casos/articulos/seriec_154_esp.pdf [fecha de visita: 20 de febrero de 2018], párrafo 124. tiva OC-7/86. Disponible en: http://www.corteidh.or.cr/docs/opiniones/seriea_07_esp.pdf [fecha de visita: 20 de febrero de 2018], pfo. 14.
} 
enmienda y que esa obligación pesaba sobre dicho Estado desde su ratificación de la Convención y no quedaba suspendida ni condicionada a la dictación de una ley interna que estableciera las condiciones de la rectificación ${ }^{27}$. Pero esta interpretación que hace la Corte sobre las obligaciones internacionales asumidas por Costa Rica no se refiere al tema de la autoejecutabilidad de la Convención en el derecho interno, por cuanto ella misma reconoció que ese asunto del efecto de la Convención en el derecho costarricense se refería a una decisión que competía exclusivamente a las autoridades nacionales. Esto último es lo que en su voto disidente los jueces Nikken y Nieto Navia intentan subrayar ${ }^{28}$. Esta posición también fue compartida por el juez Buergenthal ${ }^{29}$.

Por eso resulta un tanto sorprendente que Eduardo Jiménez de Aréchaga haya sido el iniciador de una incorrecta lectura de la Opinión Consultiva OC-7/86, afirmando que esta declaraba el carácter autoejecutable de la Convención Americana en los ordenamientos jurídicos de los Estados Parte. En efecto, en un artículo publicado en 1988 por el Instituto Interamericano de Derechos Humanos, Jiménez de Aréchaga declara que la opinión consultiva sanciona la autoejecutabilidad de la Convención Americana ${ }^{30}$. Sin embargo, la tradición interpretativa que inició Jiménez de Aréchaga en 1988, es contradicha por la propia Corte Interamericana en 1994. En la Opinión Consultiva sobre Los Efectos de las Leyes Contrarias a la Convención, la Corte insiste en que los efectos internos de una ley contraria a la Convención deben ser determinados por los jueces nacionales de acuerdo a las reglas establecidas en su propio derecho interno:

34. La pregunta se refiere únicamente a los efectos jurídicos de la ley desde el punto de vista del derecho internacional, ya que no le corresponde a la Corte pronunciarse sobre los mismos en el orden interno del Estado interesado. Esa determinación compete de manera exclusiva a los tribunales nacionales y debe ser resuelta conforme a su propio derecho ${ }^{31}$.

CIDH, Opinión Consultiva OC-7/86, pfos. 23 y 28.

Voto de los jueces Nikken y Nieto Navia, pfos. 14 y 15.

Voto del Juez Buergenthal, párrafo 1.

JimÉnez De ARÉCHAGA, Eduardo (1988) "La Convención Interamericana de Derechos Humanos como Derecho Interno". Revista del Instituto Interamericano de Derechos Humanos, No 7 , pp. 25-41, 38 .

31 Corte Interamericana de Derechos Humanos. 9 de diciembre de 1994. Opinión Consultiva OC-14/94. Disponible en: http://www.corteidh.or.cr/docs/opiniones/seriea_14_esp. pdf [fecha de visita: 20 de febrero de 2018] 
A pesar de los intentos de la propia Corte Interamericana de no inmiscuirse en la forma de recepción de la Convención en los derechos internos de los Estados, la doctrina se encargó con posterioridad de construir la tesis de la obligación de dar efecto directo al Pacto de San José. Esta tesis es compartida, entre otros muchos, por Antonio Cançado Trindade $^{32}$, Humberto Nogueira ${ }^{33}$, y Germán Bidart Campos ${ }^{34}$.

Con todo, finalmente sería la propia Corte Interamericana, durante la Presidencia del Juez Antonio Cançado Trindade, la que crearía la tesis aún más controvertida del control de convencionalidad. Esta tesis se basa en la autoejecutabilidad de la Convención, pues exige que ella sea aplicada por los tribunales nacionales sin necesidad de medidas administrativas o legislativas que la implementen de forma alguna, pero va mucho más allá, estableciendo la obligación de cada juez nacional en los Estados Parte de realizar una revisión de compatibilidad entre la legislación interna y la Convención, y que le obliga (según la Corte Interamericana) a dejar de aplicar la ley interna si esta contradice las disposiciones del Pacto de San José.

El origen de esta nueva jurisprudencia se encuentra en la Sentencia de la Corte Interamericana en el caso Almonacid Arellano y otros v. Chile (2006), en cuyo párrafo 124 se lee:

La Corte es consciente que los jueces y tribunales internos están sujetos al imperio de la ley y, por ello, están obligados a aplicar las disposiciones vigentes en el ordenamiento jurídico. Pero cuando un Estado ha ratificado un tratado internacional como la Convención Americana, sus jueces, como parte del aparato del Estado, también están sometidos a ella, lo que les obliga a velar porque los efectos de las disposiciones de la Convención no se vean mermadas por la aplicación de leyes contrarias a su objeto y fin, y que desde un inicio carecen de efectos jurídicos. En otras palabras, el Poder Judicial debe ejercer una especie de "control de convencionalidad" entre las normas jurídicas internas que aplican en los casos concretos y la Convención Americana sobre Derechos Humanos. En esta tarea, el Poder Judicial debe tener en cuenta no solamente el tratado, sino también la interpretación que del mismo ha hecho la Corte Interamericana, intérprete última de la Convención Americana.

\footnotetext{
32 Cançado Trindade, Antonio (2001) Los Derechos Humanos en el Siglo XXI. Santiago: Editorial Jurídica, pp. 559, pp. 283-285.

33 Nogueira, Humberto (1997) "Los Tratados Internacionales en el Ordenamiento Jurídico Chileno”. Ius et Praxis, vol. 2 No 2, pp. 9-43.

34 Bidart Campos, Germán (1994) La interpretación del sistema de Derechos Humanos. Buenos Aires: Editorial Ediar, pp. 272, p. 185.
} 
Posteriormente la obligación de realización de un control de convencionalidad ha sido declarada en varios otros fallos de la Corte Interamericana ${ }^{35}$. La envergadura del efecto de la teoría del control de convencionalidad no tiene precedentes: al ratificar la Convención Americana, los Estados habrían otorgado a sus jueces nacionales el poder de revisar las leyes del país, sin perjuicio de que el sistema de distribución de competencias establecido en la respectiva constitución política jamás hubiera contemplado este tipo de competencias para el Poder Judicial. Los alcances de la teoría del "control de convencionalidad" son demasiados amplios. Tal vez por eso, en algunas sentencias, la Corte Interamericana ha tratado de limitar sus efectos seńalando que el control de convencionalidad se debe ejercer conforme a las competencias que los respectivos sistemas jurídicos entregan a los jueces nacionales ${ }^{36}$. Pero en otras sentencias la teoría se vuelve a expandir, como cuando la Corte señala que todo órgano del Estado debe realizar el control de convencionalidad ${ }^{37}$, que dicho control debe considerar la interpretación que ha efectuado la propia Corte de la Convención ${ }^{38}$, y también lo que ella haya dicho en sus opiniones consultivas ${ }^{39}$.

Esta supuesta obligación no se encuentra establecida en ninguna parte de la Convención Americana ${ }^{40}$. En efecto, no existe ninguna norma del tratado que obligue a los jueces nacionales a realizar este tipo de control. Pedro Nikken ha reconocido que la Corte "no ha expresado el fundamento legal del control de convencionalidad" agregando que "ni tiene por qué hacerlo, pues se trata de una conclusión inseparable del deber jurídico que pesa sobre los Estados parte en la $\mathrm{CADH}$ de hacer plenamente efecti-

35 Para una revisión de las versiones del "control de convencionalidad" que ha manejado la propia Corte Interamericana, ver Contreras, Pablo (2014) "Control de Convencionalidad y una Nueva Constitución: Hacia una Lectura Competencial del Control de Convencionalidad”. En: Chia, Eduardo y Quezada, Flavio (editores), Propuestas para una Nueva Constitución. Santiago: Instituto Igualdad, Fundación Friedrich Ebert, Universidad de Chile, pp. 155 y ss.

36 Corte Interamericana de Derechos Humanos. Sentencia de 24 de noviembre de 2006. "Trabajadores Cesados del Congreso (Aguado Alfaro y otros) vs. Perú". Disponible en: http://www.corteidh.or.cr/docs/casos/articulos/seriec_174_esp.pdf [fecha de visita: 20 de febrero de 2018]

37 Corte Interamericana de Derechos Humanos. Sentencia de 24 de febrero de 2011. "Caso Gelman vs. Uruguay". Disponible en: http://www.corteidh.or.cr/docs/casos/articulos/ seriec_221_esp1.pdf [fecha de visita: 20 de febrero de 2018]

38 Corte Interamericana de Derechos Humanos. Sentencia de 26 de noviembre de 2010. "Caso Cabrera García y Montiel Flores vs. México". Disponible en: http://www.corteidh. or.cr/docs/casos/articulos/seriec_220_esp.pdf [fecha de visita: 20 de febrero de 2018]

39 Corte Interamericana de Derechos Humanos. 19 de agosto de 2014. Opinión Consultiva OC-21/14. Disponible en: http://www.corteidh.or.cr/docs/opiniones/seriea_21_esp.pdf [fecha de visita: 20 de febrero de 2018]

40 Fuentes (2008) 487-488. 
va la normativa convencional, dentro de su jurisdicción” ${ }^{41}$, contradiciendo su postura inicial respecto a la aplicación interna de la Convención (su posición en la OC-7/86). Es decir, la teoría del control de convencionalidad, con todas sus implicancias, solo se fundamentaría en el deber genérico de hacer efectivas las normas de la Convención.

La tendencia de la Corte Interamericana por seguir fortaleciendo la autoejecutabilidad de la Convención sin un fundamento específico en la propia Convención, se sigue desarrollando en su jurisprudencia reciente. Es así como en la Opinión Consultiva OC-24/17, de 24 de noviembre de 2017, la Corte llega a indicarle en forma específica y detallada a Costa Rica cómo debe interpretar una disposición del Código Civil costarricen$\mathrm{se}^{42}$. Los tribunales internacionales no formulan normalmente interpretaciones concretas del derecho interno, sino que se limitan a determinar si normas internas son o no compatibles con las obligaciones internacionales del Estado, o hacen apreciaciones generales sobre los criterios que debería cumplir tal legislación para ajustarse a las expectativas del derecho internacional, pero nunca han ordenado a los jueces nacionales aplicar una interpretación concreta de las reglas internas. Los tribunales internacionales no son cuarta instancia ni tienen la competencia para interpretar normas internas. Con esto, la Corte Interamericana ha ignorado la teoría de la deferencia a las competencias del Estado.

El control de convencionalidad y sus efectos colaterales, como este poder que se ha arrogado la Corte para decirle a los jueces nacionales cómo deben interpretar en concreto las reglas de su sistema jurídico, entonces, son mecanismos que sí tienen el potencial de que se cumpla la profecía: "el futuro del derecho internacional es doméstico." No solo los jueces nacionales podrían entender derogada tácitamente la legislación nacional que se contrapone con el Pacto de San José, sino que además lo deberían hacer siguiendo la interpretación que del mismo ha hecho la Corte Interamericana, que para los efectos se podría transformar en una Corte Suprema transnacional en el ámbito interamericano ${ }^{43}$.

$41 \quad$ Nikken, Pedro (2013) "El Derecho Internacional de los Derechos Humanos en el derecho interno”, Revista del Instituto Interamericano de Derechos Humanos, vol. 57, pp. 11-68, p. 60. Corte Interamericana de Derechos Humanos. 14 de noviembre de 2017. Opinión Consultiva OC-24/17. Disponible en: http://www.corteidh.or.cr/docs/opiniones/seriea_24_ esp.pdf [fecha de visita: 20 de febrero de 2018], párrafo 70.

43 Dulitzky, Ariel (2015) "An Inter-American Constitutional Court? The Invention of the Conventionality Control by the Inter-American Court of Human Rights", Texas International Law Journal, vol. 50, pp. 45-93, 47-48. 


\section{3) CHILE: FALTA DE REGLAS Y FALTA DE DOCTRINA}

En Chile no hay reglas constitucionales explícitas sobre la forma en que el derecho internacional puede ingresar al ordenamiento jurídico ${ }^{44}$. Tampoco hay regla explícita sobre la llamada "jerarquía" de los tratados en el sistema jurídico interno, es decir, cómo ellos se vinculan con las otras normas del sistema (Constitución, leyes, decretos y reglamentos), ni cómo se deben solucionar los conflictos normativos que se susciten entre tratados y reglas internas. Finalmente, sobre la posibilidad de que los tratados sean aplicados directamente por los tribunales y otros órganos, la Constitución también guarda silencio.

Los tratados internacionales se promulgan por el Presidente de la República y se los ordena cumplir dentro del ordenamiento jurídico nacional. Incluso a veces se utiliza la fórmula de estilo que los ordena cumplir como "ley de la república" ${ }^{5}$. Por otra parte, los tribunales desde hace mucho tiempo asumieron que los tratados tenían, por lo menos, jerarquía de ley ${ }^{46}$. Sin embargo, en la propia Constitución hay argumentos para sostener que algunos tratados podrían tener jerarquía inferior a la ley, esto es, jerarquía de reglamento. En efecto, en el artículo 54 de la Constitución (antes artículo 50) se dispone que hay tratados que se suscriben en función de la potestad reglamentaria del Presidente de la República. Siguiendo, entonces, el esquema de distribución de competencias que realiza la Constitución entre distintos órganos del Estado, sería razonable concluir que los tratados que suscribe el Presidente sin necesidad de aprobación del Congreso deberían tener jerarquía reglamentaria ${ }^{47}$.

Aldunate señala que es imposible que el Presidente negocie y suscriba tratados en virtud de la potestad reglamentaria, porque esa es una facultad unilateral y al suscribir tratados se ejerce la facultad negociadora y contractual del Estado en su esfera externa ${ }^{48}$. Sin embargo, lo que Aldunate olvida es que los tratados son normas que tienen doble vida: una en el ámbito internacional donde constituyen normas que regulan las

\footnotetext{
44 Aldunate, Eduardo (2010) "La posición de los tratados internacionales en el sistema de fuentes del ordenamiento jurídico chileno a la luz del derecho positivo", Ius et Praxis, vol. 16 No 2 pp. 185-210, 192.

45 Aldunate (2010) 198.

46 Entre las primeras sentencias de la Corte Suprema que resolvieron que los tratados debían equipararse con la ley véase: Godoy y otros con Fisco, Revista de Derecho y Jurisprudencia, tomo XII, 2a parte, sección 1, p. 104; y Sucesión Juan Gardaix con Fisco, Revista de Derecho y Gaceta de los Tribunales, 1921, Primer Semestre, p. 22.

47 Fuentes (2015) 177. Ver también Ribera, Teodoro; Gornig, Gilbert (2016) Relaciones entre el derecho internacional público y el derecho interno en Europa y Sudamérica. Pamplona: Thomson Reuters, pp. 195, pp. 122-125. 
relaciones entre Estados, y una vida interna, donde constituyen reglas que pueden establecer derechos para los individuos frente al Estado o incluso obligaciones dentro del sistema jurídico nacional. Si los tratados han de tener efectos normativos internos, se debe tener presente que el sistema de creación de las normas que regulan las relaciones jurídicas dentro del país obedece a una distribución de competencias contenida en la Constitución y que ese sistema tiene por objeto una distribución democrática del poder. Los tratados, en tanto normas que pueden tener efectos en la esfera interna del Estado, no pueden quedar ajenos a la distribución de competencias del sistema jurídico chileno. En unos casos, el efecto normativo del tratado al interior del sistema chileno justifica el trámite de la aprobación de los tratados por el Congreso y en otros no; de la misma manera en que algunas normas deben ser aprobadas por el Congreso y otras solo son elaboradas por el Presidente y se llaman decretos y reglamentos.

En Chile, la jurisprudencia y la doctrina determinaron que los tratados pueden incorporarse al sistema jurídico nacional ${ }^{49}$. Respecto de la pregunta de la posición relativa de los tratados en comparación con las otras normas del sistema, la primera aproximación jurisprudencial fue que estos tienen jerarquía de ley. Sabemos que los argumentos no fueron muy sofisticados, ya que las sentencias respectivas simplemente se basaron en el hecho de que en el trámite de la aprobación interna intervenía el Congreso para concluir que los tratados "son verdaderas leyes" 50 . Así las cosas, por bastante tiempo los tratados convivieron al lado de las demás leyes de la República, de tal manera que, en teoría, podía aplicarse el efecto de la derogación tácita en caso de contradicción entre un tratado y una ley posterior (y viceversa).

Posteriormente, después de la recuperación de la democracia y a partir de la reforma del inciso $2^{\circ}$ del artículo 5 de la Constitución comienza la discusión sobre la jerarquía de los tratados, con el movimiento de derechos humanos abogando para que a los tratados de derechos humanos se asignara una jerarquía superior a las leyes e, incluso para algunos, superior a la Constitución ${ }^{51}$. No es el objetivo de este artículo discutir los argumentos formulados para apoyar la jerarquía supralegal de los tratados

\footnotetext{
49 Ribera/Gornig (2016) 120.

$50 \quad$ Ver las sentencias citadas en supra n. 59.

51 Nogueira (1997). Raúl Bertelsen, por ejemplo, argumenta la jerarquía supralegal pero infraconstitucional de los tratados. Ver, BerTELSEN, Raúl (1996) "Rango jurídico de los tratados internacionales en el derecho chileno", Revista Chilena de Derecho, Vol. 23 Nos. 2 y 3 , Tomo I, pp. 211-222. Véase también Bustos, Crisologo (1995) "Naturaleza jurídica de los tratados y su relación jerárquica con la ley”, RDUV, Nos. 17-19, Tomo III, pp. 181-194.
} 
en el sistema jurídico chileno ${ }^{52}$. Lo que es necesario destacar es que la discusión sobre la jerarquía supralegal de los tratados perdería sentido si los tratados dejaran de ser invocables directamente ante los tribunales nacionales. Es decir, las consecuencias prácticas de la supralegalidad de los tratados dependen de su autoejecutabilidad. Y por eso resulta curioso que la jurisprudencia pero, sobre todo, la doctrina, hayan destinado tan pocos estudios al tema de la autoejecutabilidad.

Como ya se dijo, la Constitución no contiene ninguna regla relativa a la autoejecutabilidad de los tratados. Pero ya la jurisprudencia chilena de principios del siglo XX aplicaba directamente tratados, en algunas situaciones especiales, como sucedió en Godoy y otros con Fisco (1913) y en Sucesión Juan Gardaix con Fisco (1921). Con la ratificación por parte de Chile de los tratados de derechos humanos, la tesis de la autoejecutabilidad se vería reforzada. Así, siguiendo la tesis de Jiménez de Aréchaga, el Pacto de San José fue considerado en Chile como un tratado directamente aplicable ${ }^{53}$. Posteriormente, en la Sentencia Rol 309 (2000) el Tribunal Constitucional intenta elaborar un fundamento para la distinción entre tratados autoejecutables y tratados que no tienen tal carácter:

$48^{\circ}$ [...] Los tratados, para su aplicación en el orden interno de un pais, pueden contener dos tipos de cláusulas, denominadas por la doctrina "self executing" y "non self executing".

Las primeras, son las que tienen el contenido y precisión necesarias que las habilita para ser aplicadas sin otro trámite como fuente del derecho interno. En otros términos, son autosuficientes, y entran a la legislación nacional cuando el tratado que las contiene se incorpora al derecho vigente.

Las segundas, son aquellas que requieren para su entrada en vigencia de la dictación de leyes, reglamentos o decretos que las implementen $y$, en tal evento, las haga aplicables como fuente del derecho interno. En otras palabras, imponen la obligación al Estado, para que en uso de sus potestades públicas, sancione la normativa necesaria para que por esa via les dé vigencia efectiva. [...]

Como se puede apreciar, el criterio descansa en el texto del tratado. $\mathrm{Si}$ tal texto es suficientemente claro, en el sentido que permita su aplicación directa por los tribunales, entonces el tratado es autoejecutable. Pero

52 Sobre esta materia, véase Fuentes (2008), (2014) y (2015).

53 Irigorn, Jeannette (1996) "La Convención Interamericana como Derecho Interno Chileno”, Revista Chilena de Derecho, vol. $23 \mathrm{No}^{\circ} 2$ y 3, tomo I, pp. 299-307. 
descansar en este criterio, para responder una pregunta que debería ser respondida por la Constitución, significa delegar la respuesta en los Estados Parte del tratado, y asumir erradamente que los respectivos poderes ejecutivos que negocian los tratados tienen competencia para definir una cuestión que debería corresponder al poder constituyente de cada Esta$\mathrm{do}^{54}$. En el Reino Unido, por ejemplo, por aplicación del principio constitucional de supremacía parlamentaria, los tratados simplemente están impedidos de tener efecto directo y el texto de los tratados negociado por el Foreign Office no puede modificar esta regla ${ }^{55}$. Además, lo más probable es que los poderes ejecutivos al negociar un tratado ni siquiera hayan tenido intención de responder a la cuestión sobre la autoejecutabilidad del mismo en los respectivos ordenamientos jurídicos nacionales ${ }^{56}$. En los países en los que opera la autoejecutabilidad, si bien el texto del tratado no se emplea para determinar el efecto directo, cumple de todas maneras un rol como criterio para limitar la autoejecutabilidad, como se explica más adelante.

Por lo tanto, si en Chile no tenemos reglas explícitas sobre autoejecutablidad de los tratados en la Constitución, ni tampoco una doctrina que haya construido una teoría sobre la autoejecutabilidad, es tiempo entonces de elaborar una.

\section{4) UN ESBOZO PARA UNA TEORÍA SOBRE LA AUTOEJECUTABLIDAD DE LOS TRATADOS EN CHILE}

Cualquier teoría sobre la autoejecutabilidad de los tratados en el sistema jurídico chileno debe partir con un análisis de la Constitución Política, considerando los artículos que se refieren a los tratados, la práctica constitucional en estas materias y la distribución de competencias entre los distintos órganos del Estado.

La regulación que hace la Constitución de los tratados se refiere fundamentalmente a dos cosas: a determinar quién tiene el poder de negociar los tratados y de manifestar el consentimiento del Estado en el ámbito internacional, y a otorgar un rol al Congreso antes de la manifestación de este consentimiento. Adicionalmente, el inciso segundo del artículo 5

\footnotetext{
54 Correa, Rodrigo (2001) "Tratados Internacionales bajo el Embrujo de Brown". En: D'Alessio, Andrés (Ed.) Estado de derecho y democracia: un debate acerca del rule of law. Buenos Aires: Editores del Puerto, p. 259.

55 Ver, en este sentido, Higgins, Rosalyn (2009) Themes and Theories, Selected Essays, Speeches and Writings in International Law. Oxford: Oxford University Press, pp. 812-821; SHAW (2008) 148-157.

56 VÁsQuez (2008) 635.
} 
de la Constitución dispone que es obligación de los órganos del Estado respetar y promover los derechos que emanan de la naturaleza humana, garantizados por la Constitución así como por los tratados ratificados por Chile y que se encuentren vigentes.

Los tratados se negocian con otros países, en conferencias internacionales o en reuniones más restringidas con los países que desean suscribir un determinado acuerdo. La Constitución reconoce que las negociaciones internacionales requieren un interlocutor que pueda representar la voz unívoca del país. Por eso, las negociaciones no están entregadas al Poder Legislativo, sino al Presidente de la República (artículo 32 No. 15). El Congreso solo participa, una vez que el texto del tratado ya ha sido negociado y su rol es el de autorizar la manifestación del consentimiento del Estado en obligarse por un tratado (artículo 54). A partir de estas reglas se puede concluir que los tratados no son verdaderas leyes porque el Congreso se limita a aprobarlos o rechazarlos ${ }^{57}$. Respecto de los tratados no hay realmente deliberación.

Por otra parte, la Constitución distribuye el poder del Estado entre los distintos órganos y determina a quién le corresponde el poder de dictar leyes. Este poder está entregado al Congreso Nacional (artículo 63). Esto es lo que la doctrina constitucional y administrativa ha denominado "reserva de ley": un conjunto de materias que el poder constituyente entrega de manera exclusiva al ámbito del legislador. Como seńala Luis Cordero, la reserva de ley supone que

[N]i la ley puede definir libremente su ámbito de actuación regulando o dejando de regular unas y otras materias ni el reglamento puede actuar a su arbitrio en todas las materias no ocupadas por el legislador y ello porque la norma constitucional exige que la regulación de determinadas materias se lleve a cabo precisamente por la ley ${ }^{58}$.

En otras palabras, una de las funciones de la reserva de ley es constreñir la actuación del legislador "impidiéndole que distribuya competencias normativas sobre el núcleo esencial de la materia sujeta a reserva" ${ }^{29}$. Parte

57 Como ha seńalado el propio Tribunal Constitucional, de acuerdo a las reglas establecidas en la Constitución, "el tratado debe aprobarse o desecharse como un todo sin que sea admisible que el Parlamento le introduzca modificaciones". Tribunal Constitucional. Sentencia de 4 de agosto de 2000. Rol N $309-2000$. Disponible en: https://www.tribunalconstitucional. cl/ver2.php?id=310 [fecha de visita: 20 de febrero de 2018], considerando $11^{\circ}$.

58 Cordero, Luis (2015) Lecciones de Derecho Administrativo. Santiago: Thomson Reuters, par. 89.

59 Cazor, Kamel; Guiloff, Matías (2011) "La reserva de ley y la necesidad de redefinir su función en el estado constitucional chileno”. En: Anuario de Derecho Público, Santiago: Ediciones UDP, pp. 478-501, p. 487. 
de los fundamentos que la doctrina ha sostenido para la existencia de la reserva de ley es el resguardo del principio democrático: es una garantía de que ciertas materias serán reguladas a través del procedimiento legislativo, que expresa el pluralismo democrático dados los distintos sectores representados en el Parlamento ${ }^{60}$.

En este contexto, la pregunta relevante para los efectos de la autoejecutabilidad debería ser si la Constitución permite o no que las materias de ley sean reguladas por tratados. Si bien la Constitución acepta que los tratados puedan versar sobre materias propias de ley, eso no quiere decir que acepte que los tratados puedan regular directamente materias propias de ley. Cuando el artículo 54 de la Constitución emplea el criterio "materias propias de ley" lo hace con el único objeto de determinar si la manifestación del consentimiento del Estado en obligarse por un tratado requiere o no la autorización del Congreso. De hecho, esta manifestación del consentimiento del Estado no siempre requiere la autorización del Congreso y es así como el artículo 54 dispone que:

Las medidas que el Presidente de la República adopte o los acuerdos que celebre para el cumplimiento de un tratado en vigor no requerirán de nueva aprobación del Congreso, a menos que se trate de materias propias de ley. No requerirán de aprobación del Congreso los tratados celebrados por el Presidente de la República en el ejercicio de su potestad reglamentaria.

Como se puede apreciar, el artículo 54 de la Constitución no establece ningún vínculo entre el trámite de aprobación de los tratados y la autoejecutabilidad de los mismos. El quórum de aprobación y la propia intervención del Congreso se piensan desde el punto de vista de la necesidad de dar cierta participación al Poder Legislativo en el proceso de celebración de los tratados; pero ni esta participación ni el respectivo quórum de aprobación se han establecido pensando en la autoejecutabilidad. De hecho, podría tratarse de un tratado que no es autoejecutable, como lo sería un tratado meramente programático, y si este tratara materias propias de ley, igualmente requeriría la aprobación del Congreso y el quórum respectivo del artículo 66.

Ahora, tratándose de la ley y de las competencias del Congreso, la disposición relevante es el artículo 63 que dispone cuáles son las materias reservadas a la ley. A partir de esta disposición se puede elaborar un argu-

60 Melero Alonso, Eduardo (2004) "La flexibilización de la reserva de ley". En: Revista Jurídica 10, Madrid: Universidad Autónoma de Madrid, pp. 109-132, pp. 114-115. 
mento plausible, fundado en el propio texto de la Constitución, según el cual, respecto de las materias de ley nuestro ordenamiento constitucional no contempla que ellas puedan ser reguladas por tratados o por normas internacionales. Es decir, el artículo 63 de la Constitución puede leerse en el sentido de que en Chile, la regla general, tratándose de materias propias de ley, es que los tratados no son autoejecutables. Esta regla solo se modificaría respecto de los tratados de derechos humanos en atención a que el artículo 5 inciso segundo de la Constitución dispone que los derechos allí establecidos deben ser respetados y promovidos por todos los órganos del Estado. El artículo 5 debe leerse en forma armónica con el artículo 63. Ambas normas tienen jerarquía constitucional y coexisten en el mismo texto. Esto permite leer el artículo 5 inciso segundo en el sentido que ciertas materias de ley, las referidas a los derechos fundamentales que derivan de la naturaleza humana, podrían ser reguladas en Chile por tratados internacionales. Es así como, en cuanto al deber de respeto de los derechos humanos contenidos en tratados internacionales que obligan a Chile los órganos del Estado están directamente obligados a respetarlos y, en ese sentido, en principio, estos tratados serían autoejecutables. Decimos en principio, por cuanto a veces el respeto, así como la promoción de los derechos humanos, requieren que se dicten normas adicionales, se establezcan procedimientos o se creen nuevos órganos, y en ese caso un tratado de derechos humanos que, en principio podría haber sido autoejecutable, no lo sea en definitiva tomando en cuenta estos criterios adicionales.

Como se habrá apreciado más arriba, el artículo 54 de la Constitución permite que el Presidente suscriba tratados en función de su potestad reglamentaria, tanto autónoma como de ejecución. Estos tratados serían también en principio autoejecutables, en la medida que establezcan normas tales que puedan aplicarse directamente en Chile. En este caso, no existiría inconveniente para la autoejecutabilidad en la medida que la regulación de estas materias cae dentro de la potestad reglamentaria ${ }^{61}$. Es decir, así como el Presidente de la República puede regular estas materias mediante decretos o reglamentos, también lo puede hacer a través de tratados que negocie con otros países.

61 Existe controversia en la doctrina de derecho público acerca de la relación entre ley y reglamento y cuál es el alcance de este último. No interesa aquí entrar en ese debate. Sin embargo, cabe hacer presente que nuestra postura no implica restringir el ámbito de acción de la potestad reglamentaria. De hecho, en la medida que los tratados versen sobre materias que pueden ser objeto de reglamento, ellos serán, en principio, autoejecutables sin necesidad de dictación de medida alguna. Sobre la relación entre ley y reglamento, véase Guiloff, Matías (2012) "Operativizando la relación ley-reglamento: una propuesta de redefinición del rol de la reserva legal”. En: Revista de Derecho Vol. XXV, No. 1, pp. 127-147. 
A pesar de la interpretación que se ha dado en los párrafos anteriores, en el sentido que la Constitución no reconoce la autoejecutabilidad de los tratados que versan sobre materias de ley, la práctica constitucional chilena ha tomado un camino diferente, pronunciándose a favor de la autoejecutabilidad de todo tipo de tratados. La Corte Suprema ha declarado la autoejecutabilidad de varios tratados ${ }^{62}$ y el Tribunal Constitucional también ${ }^{63}$. La Contraloría General de la República también se ha pronunciado en el sentido de considerar que los tratados son generalmente autoejecutables en Chile ${ }^{64}$. Esta práctica se ha basado en el simple hecho de que los tratados se han asimilado a la ley y ha omitido realizar un análisis basado en la lógica que sustenta la distribución de competencias contenida en la Constitución.

Esa distribución de competencias entre los distintos órganos del Estado funciona del siguiente modo. El poder de hacer leyes radica en el Congreso Nacional. El artículo 63 señala cuáles son las materias de ley. Ni el Presidente de la República ni el Poder Judicial pueden dictar leyes. La razón se encuentra en el hecho de que la ley es una manifestación de la voluntad soberana y en Chile la soberanía radica en el pueblo. El Congreso permite que este pueblo se manifieste a través de representantes y que los representantes deliberen sobre la creación de la ley. El Presidente, si bien es elegido por el pueblo, no es un órgano colegiado que permita la representación de las diversas visiones políticas del pueblo y no es un órgano que tome decisiones mediante la deliberación democrática. Salta a la vista, entonces, que los tratados no son una expresión de la voluntad soberana. De hecho el Tribunal Constitucional ya ha reconocido que los tratados no son verdaderas leyes ${ }^{65}$. Permitir que los tratados, que son negociados y ratificados por el Presidente, y frente a los cuales el Congreso solo puede adoptar una posición binaria, de "apruebo" o "rechazo", regulen por sí mismos materias propias de ley distorsiona el sistema de distribución de competencias establecido en la Constitución.

Esta es la teoría que se ha intentado esbozar: que conforme a la Constitución los tratados no tienen carácter autoejecutable en Chile, con algunas excepciones. La primera excepción se refiere a los tratados de derechos humanos por cuanto el artículo 5 inciso 2 de la Constitución

62 Corte Suprema, Sentencias Rol 2187-2009 (2011), 258-2011 (2011), 14343-2016 (2016). Disponibles en: http://suprema.poderjudicial.cl/SITSUPPORWEB/InicioAplicacion.do [fecha de visita: 21 de febrero de 2018]

63 Tribunal Constitucional, Sentencias Rol 309 (2000), 383 (2003), 1483 (2009), 1504 (2009), 1988 (2011). Disponibles en https://www.tribunalconstitucional.cl/sentencias/ busqueda-basica [fecha de visita: 21 de febrero de 2018]

64 CGR, Dictamen No. 61.817 de 2006 y Dictamen No. 26.154 de 2008.

65 TC. Rol 1288-2009, considerando quincuagésimo segundo: "el tratado internacional no es propiamente una ley". 
prescribe que los órganos del Estado están limitados en su accionar por estos tratados. Pero esto no significa que todos los tratados de derechos humanos sean autoejecutables porque, como se verá más adelante, existen factores adicionales que podrían determinar que el tratado no se pueda aplicar directamente en el sistema jurídico chileno. La segunda excepción está referida a los tratados negociados y suscritos en virtud de la potestad reglamentaria del Presidente de la República. Respecto de estos tratados también podrían intervenir ciertos factores que lleven a la conclusión que algunos de ellos finalmente tampoco puedan tener efecto directo en Chile. En la siguiente sección se explicará por qué puede ser que un tratado que, en principio, podría ser autoejecutable, finalmente no lo sea.

\section{5) LOS CRITERIOS RELEVANTES PARA DETERMinar LA AUTOEJECUTABILIDAD DE LOS TRATADOS}

En la sección anterior se elaboró el argumento según el cual, por regla general, la Constitución Política de la República no permite la autoejecutabilidad de los tratados que tratan materias propias de ley, por cuanto la facultad de dictar leyes en esas materias pertenece al Congreso Nacional. Sin embargo, nuestra práctica constitucional ha establecido una interpretación diferente, según la cual la regla general es la autoejecutabilidad de los tratados. En esta sección, se asumirá esta perspectiva amplia respecto de la autoejecutabilidad. Esto quiere decir que se tomará como punto de partida la autoejecutabilidad general de los tratados en el sistema jurídico chileno, pero se explorará el impacto de diversos factores que, en determinados casos, llevan a la conclusión de que a esos tratados, que en principio eran autoejecutables, tampoco debería otorgárseles tal carácter.

\section{(5.1.) El TEXTO DEL TRATAdo}

Como se dijo más arriba, el texto del tratado no es un criterio válido para determinar la autoejecutabilidad de los tratados porque, siendo una cuestión que corresponde al derecho constitucional de los Estados, la decisión sobre autoejecutabilidad no puede haber sido entregada a los poderes ejecutivos de los países negociadores del texto del tratado. Sin embargo, en la hipótesis en que estamos trabajando, es decir, partiendo de la premisa que la generalidad de los tratados son autoejecutables en Chile porque así lo ha determinado la jurisprudencia y la doctrina, hay que destacar que el texto del tratado se puede emplear para determinar 
que un tratado no es autoejecutable. El problema es que, partiendo de la regla general de la autoejecutabilidad, los operadores jurídicos se olvidan que, en algunos casos, el texto del tratado permite concluir lo contrario. A continuación se analizará un ejemplo de un acuerdo, cuyo lenguaje permite afirmar que este no es autoejecutable y, sin embargo, nuestros tribunales han fallado en sentido contrario a dicho texto, porque han olvidado interpretar el tratado en su integridad.

Nos referimos a la Convención para la Protección de la Flora, la Fauna y las Bellezas Escénicas Naturales de América de 1940 (también conocida como "Convención de Washington"). La discusión sobre los efectos de esta Convención dentro del ordenamiento jurídico chileno se suscita a propósito de las actividades que se pueden o no desarrollar en parques nacionales. El artículo III de esta Convención dispone que:

Los Gobiernos Contratantes convienen en que los límites de los parques nacionales no serán alterados ni enajenada parte alguna de ellos sino por acción de la autoridad legislativa competente. Las riquezas existentes en ellos no se explotarán con fines comerciales.

A partir de esta disposición algunas sentencias en Chile han interpretado que en los parques nacionales que se han establecido en nuestro país no se puede desarrollar actividades de explotación de recursos naturales. Así, en 1985 la Corte Suprema prohibió la extracción de agua desde el lago Chungará66.

En la misma línea de la sentencia anterior se encuentran las sentencias de la Corte de Apelaciones de Puerto Montt de 18 de agosto de 2010 recaídas en recursos de ilegalidad presentados contra las Resoluciones de la Dirección Regional de Aguas Nos. 445, 446, 447, 454, 456, 455, 457, 480,487, 488, 491, 502, todas de 2010, que concedían derechos de aprovechamiento de aguas sobre el río Chaiquil, ubicado al interior del Parque Nacional Chiloé, en la Región de Los Lagos. La sentencias respectivas fueron objeto de recursos de casación en el fondo ante la Corte Suprema. El máximo tribunal confirmó las conclusiones de la Corte de Puerto Montt, sosteniendo que la Convención de Washington establece una exclusión para las actividades comerciales en parques nacionales (Considerando Décimo) ${ }^{67}$.

66 Corte Suprema. 19 de diciembre de 1985. Rol 19.824. "Palza Corvacho con Dirección de Riego de la Primera Región y otros". Revista de Derecho y Jurisprudencia, tomo LXXXII (1985), nº 3, sección 5, p. 264.

67 Ver Corte Suprema, Rol 7423-2010. Lo mismo se puede apreciar en el Rol 7424-2010 $\left(\right.$ Considerando $9^{\circ}$ ); Rol 7425-2010 (Considerando 10²); Rol 7426-2010 (Considerando 
Existen también algunos dictámenes de Contraloría en los que se interpreta la Convención de Washington en el sentido de establecer una obligación de carácter imperativa de prohibir la explotación comercial de los recursos de los parques nacionales y consideran que esa obligación es autoejecutable. Así por ejemplo, el Dictamen 56465 de 2008 sobre Solicitud de Autorización Provisoria de la Central Hidroeléctrica Chacayes, la Contraloría aplica directamente las categorías de la Convención de Washington, seńalando que en las reservas nacionales se permite la utilización, bajo vigilancia oficial de sus riquezas naturales, en cambio en los parques nacionales se prohíbe expresamente la explotación comercial de dichas riquezas.

Pero un análisis más detenido habría permitido en todos estos casos concluir que, a partir del propio lenguaje empleado por el acuerdo, se trata de un tratado que no es autoejecutable. El artículo I define distintas zonas de protección que pueden establecer los países que ratifiquen la Convención: parques nacionales, reservas nacionales, monumentos naturales y las reservas de regiones vírgenes. Los países pueden establecer estas zonas de protección pero no están obligados a hacerlo. El artículo II, por su parte, aclara el ámbito de la obligación que asumen los Estados, que consiste simplemente en considerar incorporar estas zonas de protección, con el régimen particular establecido en la Convención, en su ordenamiento jurídico nacional. La obligación que asumen los Estados es específicamente estudiar la factibilidad de establecer estas zonas de protección en su derecho interno. Por eso que, al interpretar esta Convención no se puede olvidar lo que dice el artículo II en sus párrafos 1 y 2 :

1. Los Gobiernos Contratantes estudiarán inmediatamente la posibilidad de crear, dentro del territorio de sus respectivos paises, los parques nacionales, las reservas nacionales, los monumentos naturales, y las reservas de regiones virgenes definidos en el articulo precedente. En todos aquellos casos en que dicha creación sea factible se comenzará la misma tan pronto como sea conveniente después de entrar en vigor la presente Convención.

2. Si en algún pais la creación de parques o reservas nacionales, monumentos naturales o reservas de regiones virgenes no fuera factible en la actualidad, se seleccionarán a la brevedad posible los sitios, objetos

$10^{\circ}$ ); Rol 7427- 2010 (Considerando 9 ${ }^{\circ}$ ); 7428- 2010 (Considerando 9 ); 7429- 2010 $\left(\right.$ Considerando $9^{\circ}$ ); 7430-2010 (Considerando $10^{\circ}$ ); Rol 7431-2010 (Considerando $10^{\circ}$ ); 7432-2010 (Considerando $9^{\circ}$ ); Rol 7433- 2010 (Considerando 10 ${ }^{\circ}$ ); Rol 7435-2010 (Considerando $10^{\circ}$ ). Disponibles en: http://suprema.poderjudicial.cl/SITSUPPORWEB/InicioAplicacion.do [fecha de visita: 21 de febrero de 2018] 
o especies vivas de animales o plantas, según sea el caso, que se transformarán en parques o reservas nacionales, monumentos naturales $o$ reservas de regiones vírgenes tan pronto como a juicio de las autoridades del país, lo permitan las circunstancias (énfasis agregado).

Esta es una típica obligación programática como muchas que se contienen en los tratados medioambientales. En el caso de la Convención de Washington se debe subrayar el empleo de criterios que suavizan el carácter imperativo de las obligaciones asumidas por las partes. Así por ejemplo, se establece que los Estados estudiarán la posibilidad de crear zonas protegidas y que en los casos en que la creación sea factible esta se comenzará tan pronto como sea conveniente. Los Estados gozan de bastante discreción para determinar si pueden o no cumplir con este compromiso débil. La Convención está plagada de términos propios del soft law ${ }^{68}$. Por este motivo, muchos autores han descrito el lenguaje de la Convención como un lenguaje que es "cooperative rather than coercive" 69.

Desde este punto de vista, Chile se obligó a estudiar la posibilidad y factibilidad de crear parques nacionales en los que no se pudieran explotar las riquezas naturales con fines comerciales. Sin embargo, la legislación chilena demuestra que el legislador nacional no estableció ese tipo de parque nacional de la Convención de Washington en la legislación interna, sino un modelo distinto de parque nacional donde sí se permite la explotación de recursos naturales con fines comerciales. Así, la Ley 19.300 sobre Bases Generales del Medio Ambiente permite la realización de actividades de explotación de recursos naturales en los parques nacionales establecidos en el país, ya que seńala que los proyectos que se pretenda realizar en parques nacionales deben someterse al sistema de evaluación ambiental si son susceptibles de causar impacto ambiental. Por otra parte, los artículos 20 y 141 del Código de Aguas permiten el establecimiento de derechos de aprovechamiento de aguas en zonas protegidas y el artículo 17 No. 2 del Código de Minería dispone que se requiere la autorización del Intendente para labores mineras en parques nacionales.

Al igual que Chile, el resto de los Estados Parte de esta Convención permite actividades de extracción de recursos naturales en parques nacionales y por eso tal vez la Convención ha sido descrita como un "tratado

68 Soft Law es la denominación que recibe el conjunto de normas internacionales que se contienen en instrumentos jurídicamente no vinculantes o en los que el carácter imperativo de las normas es débil. Ver, Birnie, Patricia; Boyle, Alan; Redgwell, Catherine (2009) International Law and the Environment. Oxford: Oxford University Press, pp. 798, pp. 34-37.

69 Bowman, Michael; Davies, Peter; Redgwell, Catherine (2002) Lyster's International Wildlife Law. 2nd Edition. Cambridge: Cambridge University Press, pp. 784, p. 469. 
dormido", por cuanto parece no haber tenido mucho efecto práctico en los Estados contratantes ${ }^{70}$. El fundamento de esta opinión de algunos autores se basa precisamente en su falta de implementación en el ámbito interno ${ }^{71}$. Nuestros tribunales parecen no conocer el real estado de la Convención en el ámbito internacional ni cómo ha sido interpretada por los propios Estados Parte, ni el carácter no autoejecutable de sus disposiciones.

\section{(5.2.) REgímenes JURÍdicos QUE NO SE PUEDEN REEMPLAZAR POR LOS JUECES}

Otro criterio que puede determinar que ciertos tratados no sean autoejecutables se refiere a las limitaciones propias de la institución de la derogación tácita. En Chile, por ejemplo, hasta antes de la reforma de 1998, el Código Civil establecía la distinción entre hijos concebidos dentro o fuera del matrimonio (hijos legítimos e hijos ilegítimos, respectivamente). Los segundos se dividían entre hijos naturales del padre o madre que los hubiera reconocido, e hijos simplemente ilegítimos. El régimen de filiación, es decir, los derechos y obligaciones entre padres y madres, y sus hijos se encontraba diseńado en torno a esta distinción. Los hijos ilegítimos no gozaban de los mismos derechos que los legítimos en una serie de materias, particularmente relativas a alimentos, parentesco, y derechos sucesorios.

Como se puede apreciar, todo este régimen de filiación discriminatorio era contrario a los tratados de derechos humanos ratificados por Chile, en particular, al Pacto Internacional de Derechos Civiles y Políticos (arts. 2 y 24); a la Convención Americana sobre Derechos Humanos (arts. 1, 17 y 19); y, a la Convención de los Derechos del Niño (arts. 2, 3, 7 y 8$)$.

Otro caso similar, tiene que ver con la discriminación que hace el Código Civil hasta el día de hoy respecto de la mujer casada en sociedad conyugal que, siendo mayor de edad, no puede administrar sus bienes (artículo 1749 del Código Civil). Nuevamente se vulnera la Convención

\footnotetext{
70 Bowman/Davies/Redgwell (2002) 242.

71 Rogers, Kathleen; Moore, James (1995) "Revitalizing the Convention on Nature Protection and Wild Life Preservation in the Western Hemisphere: Might Awakening a Visionary But 'Sleeping' Treaty Be the Key to Preserving Biodiversity and Threatened Natural Areas in the Americas?". Harvard International Law Journal, vol. 36, pp. 465-508, 466. Rose, D. (1992) “The International Conservation of Latin America's Wildlife". International Environmental Affairs, vol.4, pp-18-34, 24.
} 
Americana sobre Derechos Humanos y también la Convención sobre la Eliminación de Toda Forma de Discriminación contra la Mujer.

La pregunta en estos casos es si los tratados de derechos humanos que prohíben la discriminación podrían aplicarse directamente de tal manera que los jueces nacionales pudieran entender tácitamente derogadas todas las disposiciones legislativas discriminatorias. Si eso fuera así, el problema es que el régimen jurídico de la filiación y el régimen de la sociedad conyugal, necesitarían ser reemplazados por un régimen distinto que no sea discriminatorio y no bastaría la simple derogación de disposiciones sino que habría que establecer una normativa de reemplazo. Los jueces no pueden establecer esa normativa y, en ese sentido, la derogación tácita de disposiciones discriminatorias tiene una limitación. En el derecho comparado, precisamente este criterio, la imposibilidad de que los jueces reemplacen un régimen o institución jurídica, ha sido utilizado para determinar que las disposiciones de un tratado no sean autoejecutables, porque los jueces no tienen facultades legislativas ${ }^{72}$.

\section{(5.3.) LA TIPIFICACIÓN DE DELITOS}

En Estados Unidos, donde la propia Constitución quiso que la regla general fuera la autoejecutablidad de los tratados, hay consenso en que no se podrían tipificar delitos por medio de tratados, por cuanto se trata de materias que la Constitución ha entregado expresamente al legislador ${ }^{73}$. En nuestro país, se podría decir lo mismo ${ }^{74}$. La Constitución chilena recoge el principio nullum crimen sine lege en el artículo 19 No. 3. El fundamento doctrinal para que los tipos penales y las penas deban ser establecidas por ley, radica en que es el congreso o el parlamento el órgano que, siendo más representativo, tiene la legitimidad para el justificar el ius puniendi del Estado:

La aplicación de la pena constituye una injerencia tan dura en la libertad del ciudadano que la legitimación para determinar sus presupuestos solo pueden residir en la instancia que representa más directamente al pueblo como titular del poder del Estado: el Parlamento como representación electa del pueblo ${ }^{75}$.

NollKaemper (2004) 177-179.

VÁsQuez (1995) 718.

PÉrez (2015) 109-112.

Roxin, Claus (1997) Derecho Penal Parte General, Tomo I. Traducción de Diego-Manuel Luzón Peńa et al. Madrid: Civitas, pp. 985, p. 195. 
Un ejemplo claro de que en nuestro país es necesario que la ley establezca los delitos, es que a pesar de que el Estatuto de la Corte Penal Internacional tipifica el genocidio y otras conductas que constituyen delitos contra la humanidad, para poder sancionar esas conductas en Chile, y en la medida que algunas de ellas no estaban tipificadas como tales en nuestro ordenamiento jurídico, fue necesario dictar la Ley 20.357 que tipifica el genocidio, crímenes de lesa humanidad y crímenes y delitos de guerra $^{76}$.

Lo mismo se puede decir de la Ley 20.507 que tipifica los delitos de tráfico ilícito de migrantes y trata de personas. En este caso lo interesante es que son los propios tratados que sirven de antecedente para la dictación de esta ley los que expresamente seńalan la necesidad de que cada Estado Parte tipifique los respectivos delitos en su ordenamiento jurídico interno ${ }^{77}$.

\section{(5.4.) Tratados QUe no establecen Derechos Para los PARTICULARES}

Tradicionalmente los tratados eran acuerdos que establecían derechos y obligaciones entre países, regulando la esfera externa de los Estados. La excepción la constituían los tratados que establecían derechos para individuos o grupos de individuos, como los tratados sobre las minorías o los tratados relativos al derecho humanitario. El gran cambio se produce con la irrupción de los tratados sobre derechos humanos, cuyo objetivo preciso es establecer derechos que el Estado debe respetar respecto de su propia población.

No obstante, hay un sinnúmero de tratados que no pretenden establecer derechos para particulares, sino solo derechos y obligaciones entre Estados. En este contexto, es interesante revisar los Tratados de Libre Comercio (TLC), porque el objetivo de estos es generar obligaciones

76 CÁrdenas, Claudia (2010) "La implementación de los crímenes de competencia de la Corte Penal Internacional en la Ley $\mathrm{N}^{\circ}$ 20.357”. Revista de Derecho, vol. XXIII, pp. 23-44.

77 Ver, por ejemplo, Convención sobre los Derechos del Niño (artículo 32 c): "Estipularán [los Estados Parte] las penalidades u otras sanciones apropiadas para asegurar la aplicación efectiva del presente artículo") y su Protocolo Facultativo Relativo a la Venta de Nińos, la Prostitución Infantil y la Utilización de Niños en la Pornografía (artículo 3.1: "Todo Estado Parte adoptará medidas para que, como mínimo, los actos y actividades que a continuación se enumeran queden íntegramente comprendidos en su legislación penal [...]”); y la Convención de las Naciones Unidas contra la Delincuencia Organizada Transnacional (artículo 5.1: "Cada Estado Parte adoptará las medidas legislativas y de otra índole que sean necesarias para tipificar como delito, cuando se cometan intencionalmente [...]"). 
y derechos entre Estados relativos al comercio de mercancías entre sus territorios. Las mercancías son probablemente producidas por personas naturales y jurídicas privadas en los respectivos territorios, pero el TLC establece derechos y obligaciones entre Estados. Aún más, estos acuerdos normalmente contienen su propio sistema interestatal de solución de diferencias. De hecho, el TLC de alcance más universal, que es el Acuerdo General sobre Aranceles Aduaneros y Comercio (GATT, por sus siglas en inglés), establece un sistema de solución de diferencias cuyo objetivo es uniformar la interpretación del tratado a través del Órgano de Apelación de la Organización Mundial de Comercio (OMC) y así dar seguridad jurídica a todos los Estados Parte, generando una jurisprudencia internacional robusta ${ }^{78}$. Desde esta perspectiva, se puede argumentar que los TLC no son autoejecutables ${ }^{79}$. La estructura misma de estos tratados no está pensada para que las controversias se solucionen en casos generados por particulares para defender sus intereses privados y ante jueces nacionales, que además no son expertos en las reglas internacionales sobre libre comercio y que no están comprometidos con el objetivo de la unificación de la jurisprudencia internacional en estas materias.

Para evitar que los propios jueces nacionales decidan dar autoejecutabilidad a los tratados de libre comercio, en Estados Unidos la norma interna de aprobación deja claramente establecido que no se crean mediante dichos tratados derechos para particulares reclamables ante los propios tribunales. Así es como la United States-Chile Free Trade Agreement Implementation Act, que tiene por objeto implementar el tratado en el sistema jurídico estadounidense, dispone textualmente lo siguiente:

(c) Effect of Agreement with respect to private remedies. No person other than the United States - (1) shall have any cause of action or defense under the Agreement or by virtue of Congressional approval thereof; or (2) may challenge, in any action brought under any provision of law, any action or inaction by any department, agency, or other instrumentality of the United States, any State, or any political subdivision of a State on the ground that such action or inaction is inconsistent with the Agreement ${ }^{80}$.

\footnotetext{
78 Ver el Entendimiento Relativo a las Normas y Procedimientos por los que se rige la solución de Diferencias, Anexo 2 al Acuerdo de la OMC de 1995.

79 Fuentes (2004) 576-577. Es interesante notar que la Corte Europea de Justicia ha considerado que el GATT no es un tratado autoejecutable dentro del sistema jurídico europeo. Ver Petersen, Niels (2012) "Determining the Domestic Effect of International Law through the Prism of Legitimacy". Heidelberg Journal of International Law, Vol. 72, No. 2, pp. 242244.

80 Véase: https://www.congress.gov/bill/108th-congress/house-bill/2738/text
} 
Como en Chile no hay reglas ni criterios claros sobre la autoejecutabilidad de los tratados, se han dado casos de particulares reclamando derechos ante los tribunales nacionales derivados de TLC. Por ejemplo, en el ańo 2003, la Corte Suprema conoció de la apelación en un recurso de protección en que la recurrente alegaba la vulneración del derecho de propiedad, basando su alegato en que el TLC entre Chile y Canadá había derogado tácitamente el impuesto al lujo impuesto a ciertos automóviles contenido en el Decreto Ley 825 (DL 825) que la Aduana de Osorno intentaba cobrarle. La Corte Suprema acogió el recurso declarando la autoejecutabilidad del TLC entre Chile y Canadá e interpretando que el llamado "impuesto al lujo" contenido el DL 825 se oponía a las reglas sobre trato nacional contenidas en el tratado ${ }^{81}$.

El caso demuestra la falta de conocimiento por parte de nuestros tribunales sobre la lógica de la obligación de trato nacional contenida en los TLC $^{82}$. Los TLC tienen por objeto evitar el proteccionismo, esto es, que los Estados establezcan medidas que favorezcan a los productos nacionales cuando estos compiten con los productos importados por el mercado interno. Por ese motivo, la aplicación de la obligación de trato nacional exige que se comparen dos productos similares (el nacional con el importado). En este caso, no correspondía la aplicación del tratado en cuanto a sus reglas sobre trato nacional por cuanto no hay una industria de automóviles nacionales que la Aduana quisiera proteger frente a las industrias extranjeras. El Servicio Nacional de Aduanas podría haberse defendido en este caso alegando que la aplicación de la obligación de trato nacional estaba fuera de lugar, pero antes que eso se debió haber alegado que el TLC entre Chile y Canadá era simplemente un tratado no invocable ante los tribunales nacionales.

\section{(5.5.) El OTORGAMIENTO DE FACULTADES A ÓRGANOS ESTATALES}

El artículo 7 de la Constitución dispone que: "Los órganos del Estado actúan válidamente previa investidura regular de sus integrantes, dentro de su competencia y en la forma que prescriba la ley". La pregunta que corresponde hacer es si un tratado podría otorgar competencias determinadas a los órganos del Estado para cumplir ciertas funciones rela-

Corte Suprema. Rol 375-2003, "Dictec Limitada contra Administración Aduana Osorno". Sornarajah, M. (2010) The International Law on Foreign Investment. 3rd Edition. Cambridge: Cambridge University Press, 524 pp., p. 337. 
tivas a los objetivos del tratado, siendo que esas competencias exceden lo que dispone la legislación nacional.

Un caso específico donde puede presentarse este problema se refiere al control de la pesca en alta mar. Chile es Parte de varios tratados relativos a la pesca en alta mar: (1) la Convención para la Conservación de los Recursos Vivos Marinos Antárticos (CCAMLR), (2) La Organización Regional de Pesca del Pacífico Sur, y (3) el Convenio de Nueva York sobre Poblaciones de Peces Transzonales y Altamente Migratorios. Estos tratados tienen por objeto que los Estados Parte tomen medidas que aseguren el uso sustentable de los recursos vivos de la alta mar y, para estos efectos, se establecen mecanismos para aprobar medidas de conservación de los recursos marinos que deben ser implementadas por las Partes. Estas medidas de conservación requieren también de medidas de fiscalización y sanción que aseguren su cumplimiento.

Siendo el alta mar una zona que no se encuentra sometida a la jurisdicción territorial de ningún Estado, la fiscalización y sanción debe descansar en: (i) el ejercicio de la jurisdicción por los Estados del pabellón de las naves, que es la regla general reconocida por el derecho del mar (jurisdicción en base al pabellón); (ii) el ejercicio de la jurisdicción en base al criterio de la nacionalidad de las personas involucradas en las actividades de pesca en alta mar (jurisdicción basada en la nacionalidad); (iii) el ejercicio de la jurisdicción sobre buques de bandera extranjera cuyos respectivos Estados han dado su consentimiento (jurisdicción en base al consentimiento); y, (iv) el ejercicio de jurisdicción sobre buques sin nacionalidad. En este contexto, es pertinente determinar si la Armada de Chile cuenta con las facultades para ejercer funciones de fiscalización de actividades pesqueras de buques que no enarbolan el pabellón chileno en alta mar.

El órgano específico encargado del ejercicio de competencias fiscalizadores en el mar es la Dirección General del Territorio Marítimo y de la Marina Mercante (DIRECTEMAR). Si se revisan sus competencias de acuerdo a los cuerpos normativos que la regulan (Art. 6 del Decreto con Fuerza de Ley $\mathrm{N}^{\circ} 292$ de 1953 y art. 5 de la Ley de Navegación), se puede apreciar que solo puede actuar dentro de aguas jurisdiccionales chilenas, es decir, dentro de las 200 millas marinas de la zona económica exclusiva. Respecto de actividades que ocurren en alta mar, DIRECTEMAR tiene competencia que se restringe a las naves chilenas conforme al artículo 3 de la Ley de Navegación. Se puede concluir entonces que la ley no le ha entregado competencias a DIRECTEMAR para realizar actividades de fiscalización en alta mar, salvo respecto de naves chilenas. 
Sin embargo, en materia de pesca, Chile ha dictado normas de conservación pesquera y participa de tratados que permiten la dictación de normas de conservación aplicables en zonas de alta mar y requieren de Chile el ejercicio de competencias de fiscalización y sanción. Uno de estos tratados es la CCAMLR promulgada en Chile en el ańo 1981. Respecto de la sanción y fiscalización de las normas de conservación de CCAMLR fue necesario modificar la ley para que los órganos chilenos pudieran fiscalizar y sancionar a nacionales que realizaran actividades de pesca ilegal en aguas antárticas en buques de pabellón extranjero. En efecto, el párrafo 4 del título IX de la Ley de Pesca titulado "Sanciones contra nacionales que realicen o participen actividades de pesca ilegal en aguas antárticas con naves de pabellón extranjero" se agregó el año 2011 mediante la Ley $\mathrm{N}^{\circ} 20.509$. Esta ley reconoce que Chile no tiene, en general, jurisdicción en alta mar.

Por esta razón, el que otros tratados en los que Chile es parte contemplen también medidas de conservación pesquera aplicables a zonas de alta mar y la posibilidad de fiscalizar y sancionar las infracciones a esas normas, no es suficiente para que la Armada de Chile pueda ejercer competencias fiscalizadoras y sancionadoras en un área que está más allá de las aguas donde Chile ejerce jurisdicción nacional. Por cierto no basta con el artículo 122 de la Ley de Pesca que dispone:

La fiscalización del cumplimiento de las disposiciones de la presente ley, sus reglamentos y medidas de administración pesquera adoptadas por la autoridad, será ejercida por funcionarios del Servicio y personal de la Armada y de Carabineros, según corresponda, a la jurisdicción de cada una de estas instituciones.

Conforme a lo dispuesto por este artículo 122, la Ley de Pesca no realiza ninguna determinación del área de competencias de la Armada, sino que simplemente realiza un reenvío a las otras normas que fijan el área en que la Armada puede ejercer sus funciones. Hay que recordar que la jurisdicción de la Armada, específicamente de la DIRECTEMAR, está otorgada en su Ley Orgánica y en la Ley de Navegación y solo alcanza a las aguas donde Chile ejerce jurisdicción (200 millas náuticas).

Por lo tanto, si Chile desea realizar fiscalización y sanción de conductas en virtud de la Convención de Nueva York sobre Poblaciones de Peces Transzonales y Altamente Migratorios o en base a la ORP del Pacífico Sur, es necesario realizar las modificaciones legales pertinentes para que la Armada opere con facultades fiscalizadoras y sancionatorias en esos es- 
pacios, respetando así el artículo 7 de la Constitución. No sería correcto interpretar esos tratados como autoejecutables respecto del otorgamiento de dichas facultades a la Armada porque la Constitución exige que las atribuciones de los órganos estatales sean otorgadas por ella misma o las leyes.

\section{CONCLUSIONES}

El punto de partida de este artículo ha sido llamar la atención sobre el vacío que existe en nuestra jurisprudencia y doctrina sobre el tema la autoejecutabilidad de los tratados internacionales en el sistema jurídico chileno. Como se discutió en la introducción, el efecto directo o autoejecutabilidad de los tratados consiste en que estos pueden ser aplicados por los operadores jurídicos sin necesidad de dictar legislación nacional complementaria, por lo que se trata de un asunto que tiene consecuencias prácticas de importancia en el derecho interno. Lo anterior resulta problemático en la medida en que el Poder Ejecutivo, mediante la celebración de tratados, podría regular materias reservadas al dominio legal -sin la deliberación democrática que supone el proceso de formación de leyes radicado en el Poder Legislativo- que luego podrían ser aplicadas por los tribunales de justicia. Sumado a lo anterior, dado que en Chile se considera que los tratados gozan de una jerarquía normativa superior a la de la ley, otorgaría a los tribunales nacionales el poder de aplicar tratados sin que el legislador pueda modificar posteriormente los efectos de dicha aplicación y de entender derogadas tácitamente las leyes que contradigan las disposiciones del tratado.

Como se explicó en la sección 1, la teoría de la autoejecutabilidad tuvo su origen en la práctica constitucional estadounidense. La discusión de esta teoría en la doctrina y jurisprudencia de dicho país ha considerado una serie de factores para determinar si un tratado puede o no ser aplicado directamente en el derecho interno. Este trabajo también ha intentado explicar por qué esta teoría ha encontrado tanta aceptación en Latinoamérica (sección 2). La respuesta es que dicha aceptación proviene, en parte, de los beneficios que organizaciones han encontrado en la utilización de tribunales nacionales a fin de dotar de eficacia al derecho internacional.

El caso del derecho chileno muestra ausencia de reglas y muy poca preocupación doctrinaria por este tema (sección 3). Este artículo intenta esbozar una teoría sobre la autoejecutabilidad de los tratados en Chile que 
toma como punto de partida la distribución de competencias que realiza la Constitución respecto de la creación de normas en nuestro sistema jurídico y subraya la distorsión que se genera al darle autoejecutabilidad a tratados que intentan regular materias propias de ley (sección 4). Las materias propias de ley son materias que la Constitución ha considerado que deben ser reguladas por el Congreso por cuanto en este órgano se realiza el proceso de deliberación democrática de las leyes. No se encuentra acorde a principios democráticos que el Presidente de la República pue$\mathrm{da}$, a través de los tratados que negocia con otras potencias, incorporar normas de carácter legal. Sin embargo, la tesis de este artículo se debe enfrentar a la práctica constitucional existente, la cual ha definido que la regla general en Chile es la autoejecutabilidad de los tratados (sección 4). Por este motivo, se proponen una serie de criterios que los jueces y otros operadores jurídicos nacionales deberían tener en cuenta al momento de tomar la decisión definitiva sobre la autoejecutabilidad de los tratados, tales como el texto del tratado, el caso de los regímenes jurídicos que no se pueden reemplazar por los jueces, la tipificación de delitos, la situación de tratados que no establecen derechos para los particulares y el otorgamiento de facultades a órganos estatales (sección 5). Con la aplicación de esos criterios y otros que puedan surgir, se podría comenzar a constituir una doctrina más robusta sobre la autoejecutabilidad de los tratados.

\section{BIBLIOGRAFÍA}

Aldunate, Eduardo (2010) "La posición de los tratados internacionales en el sistema de fuentes del ordenamiento jurídico chileno a la luz del derecho positivo", Ius et Praxis, ańo 16, № 2, pp. 185-210.

Bertelsen, Raúl (1996) "Rango jurídico de los tratados internacionales en el derecho chileno", Revista Chilena de Derecho, Vol. 23 Nos. 2 y 3, Tomo I, pp. 211-222.

Bidart Campos, Germán (1994) La interpretación del sistema de Derechos Humanos. Buenos Aires: Editorial EdIAR, pp. 272.

Birnie, Patricia; Boyle Alan; Redgwell, Catherine (2009) International Law and the Environment. Oxford: Oxford University Press, pp. 798.

Bowman, Michael; Davies, Peter; Redgwell, Catherine (2002) Lyster's International Wildlife Law. Cambridge: Cambridge University Press, Second Edition, pp. 784.

Bustos, Crisologo (1995) "Naturaleza jurídica de los tratados y su relación jerárquica con la ley", $R D U V$, Nos. 17-19, Tomo III, pp. 181-194. 
Cançado Trindade, Antonio (2001) Los Derechos Humanos en el Siglo XXI. Santiago: Editorial Jurídica, pp. 559.

Cárdenas, Claudia (2010) "La implementación de los crímenes de competencia de la Corte Penal Internacional en la Ley N ${ }^{\circ} 20.357$ ". Revista de Derecho, vol. XXIII, pp. 23-44.

Cazor, Kamel; Guiloff, Matías (2011) "La reserva de ley y la necesidad de redefinir su función en el estado constitucional chileno". En: Anuario de Derecho Público, Santiago: Ediciones UDP, pp. 478-501.

Conforti, Benedetto; Francioni, Francesco (1997) Enforcing International Human Rights in Domestic Courts. The Hague: Martinus Nijhoff, pp. 466.

Contreras, Pablo (2014) "Control de Convencionalidad y una Nueva Constitución: Hacia una Lectura Competencial del Control de Convencionalidad”. En: Chia, Eduardo; Quezada, Flavio (eds.), Propuestas para una Nueva Constitución, Santiago: Instituto Igualdad, Fundación Friedrich Ebert, Universidad de Chile, pp. 155-169.

Cordero, Luis (2015) Lecciones de Derecho Administrativo. Santiago: Thomson Reuters, pp. 786.

Correa, Rodrigo (2001) "Tratados Internacionales bajo el Embrujo de Brown”. En: D’Alessio, Andrés (Ed.), Estado de derecho y democracia: un debate acerca del rule of law. Buenos Aires: Editores del Puerto, pp. 249-266.

Correa, Rodrigo (2008) International Law: The View from the Republic (Tesis de doctorado no publicada). New Haven: Yale University, pp. 225.

Dulitzky, Ariel (2015) “An Inter-American Constitucional Court? The Invention of the Conventionality Control by the Inter-American Court of Human Rights". Texas International Law Journal, vol. 50, pp. 45-93.

Fuentes, Ximena (2004) "Aplicación de Tratados Internacionales en el Derecho Interno", Revista de Derecho de la Universidad Adolfo Ibánez, vol. 1, pp. 717-735.

Fuentes, Ximena (2005) "Aplicación de Tratados Internacionales en el Derecho Interno", Revista de Derecho de la Universidad Adolfo Ibánez, vol. 2, pp 1193-1200.

Fuentes, Ximena (2008) "International Law and Domestic Law: Definitely an Odd Couple", Revista Jurídica de la Universidad de Puerto Rico, vol. 77, pp. 483-505.

Fuentes, Ximena (2013) "Derecho Internacional Público. Convenios de Ginebra (1949)", Revista de Derecho de la Universidad Adolfo Ibánez, vol. 3, pp. 529-542.

Fuentes, Ximena (2014) "La jerarquía y el efecto directo del derecho internacional en el sistema jurídico chileno". En: Atria, Fernando et 
al. (eds.), Una Vida en la Universidad de Chile: celebrando al profesor Antonio Bascuñán Valdés. Santiago: Thomson Reuters, pp. 583-618.

Fuentes, Ximena (2015) "Una Nueva Constitución para Chile y el Diseño de un Esquema de Incorporación del Derecho Internacional al Sistema Jurídico Chileno". En: Chia, Eduardo; Quezada, Flavio (eds.) Propuestas para una Nueva Constitución. Santiago: Instituto Igualdad, Fundación Friedrich Ebert y Facultad de Derecho de la Universidad de Chile, pp. 171-193.

Guillof, Matías (2012) "Operativizando la relación ley-reglamento: una propuesta de redefinición del rol de la reserva legal”. En: Revista de Derecho Vol. XXV, No. 1, pp. 127-147.

Higgins, Rosalyn (2009) Themes and Theories, Selected Essays, Speeches and Writings in International Law. Oxford: Oxford University Press, pp. 1200.

IrIgoIN, Jeannette (1996) "La Convención Interamericana como Derecho Interno Chileno", Revista Chilena de Derecho, vol. $23 \mathrm{No}^{\text {s }} 2$ y 3, tomo I, pp. 299-307.

Jiménez de Aréchaga, Eduardo (1988) "La Convención Interamericana de Derechos Humanos como Derecho Interno". Revista del Instituto Interamericano de Derechos Humanos, No. 7, pp. 25-41.

Kahn, Paul W. (2011) "El derecho internacional y la comunidad". En D’Alessio, Andrés (Ed.), Estado de derecho y democracia: un debate acerca del rule of law. Buenos Aires: Editores del Puerto, pp. 267280.

Kaiser, Karen (2013) “Treaties, Direct Applicability”. En: Wolfrum, Rüdiger (Ed.), Max Planck Encyclopedia of Public International Law.

Melero Alonso, Eduardo (2004) "La flexibilización de la reserva de ley". En: Revista Juridica 10, Madrid: Universidad Autónoma de Madrid, pp. 109-132.

Nikken, Pedro (2013) "El Derecho Internacional de los Derechos Humanos en el derecho interno", Revista del Instituto Interamericano de Derechos Humanos, vol. 57, pp. 11-68.

Nogueira, Humberto (1997) "Los Tratados Internacionales en el Ordenamiento Jurídico Chileno". Ius et Praxis, vol. 2 No 2, pp. 9-43.

Nollkaemper, André (2004) "The Direct Effect of Public International Law”. En: Prinssen, Joland y Schrauwen, Annette (Eds.), Direct Effect Rethinking a Classic of EC Legal Doctrine. Groningen: Europa Law Publishing, pp. 157-180.

O'Connell, Mary-Ellen (2008) The Power and Purpose of International Law. Oxford: Oxford University Press, pp. 408.

PÉrez, Diego (2015) El efecto directo de los tratados internacionales en el derecho chileno. Memoria para optar al grado de Licenciado en 
Ciencias Jurídicas y Sociales, Facultad de Derecho, Universidad de Chile (no publicada), pp. 155.

Petersen, Niels (2012) "Determining the Domestic Effect of International Law through the Prism of Legitimacy". Heidelberg Journal of International Law, Vol. 72, No. 2, pp. 242-244.

Ribera, Teodoro; Gornig, Gilbert (2016) Relaciones entre el derecho internacional público y el derecho interno en Europa y Sudamérica. Pamplona: Thomson Reuters, pp. 195.

Rogers, Kathleen; Moore, James (1995) "Revitalizing the Convention on Nature Protection and Wild Life Preservation in the Western Hemisphere: Might Awakening a Visionary But "Sleeping" Treaty Be the Key to Preserving Biodiversity and Threatened Natural Areas in the Americas?", Harvard International Law Journal, vol. 36, pp. 465508.

Rose, D. (1992) “The International Conservation of Latin America's Wildlife", International Environmental Affairs, vol. 4, pp-18-34.

Roxin, Claus. (1997) Derecho Penal Parte General, tomo I (Traducción de Diego-Manuel Luzón Peña et al.), Madrid: Civitas, pp. 985.

Rubin, Alfred (i988) The Law Of Piracy. Rhode Island: Naval War College Press, pp. 444.

Seibert-Fohr, Anja (2001) "Domestic Implementation of the International Covenant on Civil and Political Rights Pursuant to its Article 2 para. 2". Max Plank Yearbook of United Nations Law, vol. 5, pp. 399-472.

Shaw, Malcolm N. (2008) International Law. 6th edition. Cambridge: Cambridge University Press, pp. 1542.

Slaughter, Anne-Marie (1995) "Review of Regime Theory and International Relations, Volker Rittberger and Peter Mayer". American Journal of International Law, vol. 89, № 2, pp. 454-456.

Slaughter, Anne-Marie; Burke-White, William (2006) "The Future of International Law is Domestic", Harvard International Law Journal, vol. 47, No 2, pp. 327-352.

Stoss, David L. (2016) The Death of Treaty Supremacy: An Invisible Constitutional Change. Oxford: Oxford University Press, pp. 472.

Sornarajah, M. (2010) The International Law on Foreign Investment. 3rd Edition. Cambridge: Cambridge University Press, pp. 524.

Staberock, Gerald (2011) "Human Rights, Domestic Implementation". En: Wolfrum, Rüdiger (Ed.), Max Planck Encyclopedia of Public International Law.

VÁsquez, Carlos Manuel (1995) "The Four Doctrines of Self-Executing Treaties". American Journal of International Law, vol. 89, pp. 695723. 


\section{VÁsQuez, Carlos Manuel (2008) "Treaties as Law of the Land: The} Supremacy Clause and the Judicial Enforcement of Treaties". Harvard Law Review, vol. 122, pp. 599-695.

Von Bogdandy, Armin (2008) "Pluralism, direct effect and the ultimate to say: on the relationship between international and domestic law". International Journal of Constitutional Law, Vol. 6, Nos. 3-4, pp. 397-413.

\section{FE DE ERRATAS:}

En la versión impresa de la revista se produjo una omisión de contenidos en la pág 123, luego del apartado "LA DISTINCIÓN ENTRE TRATADOS AUTOEJECUTABLES Y NO AUTOEJECUTABLES" debería aparecer lo siguiente:

El origen de la distinción entre tratados autoejecutables y no autoejecutables proviene de los Estados Unidos ${ }^{8}$. La Cláusula Sexta, párrafo 2, de la Constitución de los Estados Unidos ordenó que todos los tratados fueran considerados, en principio, autoejecutables ante los tribunales de justicia ${ }^{9}$. Esta Cláusula, conocida también como la Cláusula de la Supremacía, fue una respuesta frente a la rebeldía que mostraban los Estados de la Confederación frente al cumplimiento de los tratados negociados por el gobierno Federal ${ }^{10}$. Pero la Corte Suprema en 1829 , en Foster v. Neilson ${ }^{11}$, interpretó, basándose en el propio texto del tratado, que no necesariamente todos los tratados eran autoejecutables en Estados Unidos.

A partir de esta distinción introducida por la Corte Suprema de los Estados Unidos, entre tratados autoejecutables y no autoejecutables, se comienza a desarrollar una doctrina sobre la autoejecutabilidad de los acuerdos internacionales ${ }^{12}$. El análisis efectuado por los tribunales estadounidenses no se ha limitado sólo a interpretar el texto de los tratados. La determinación de si un tratado tiene o no efecto directo en Estados Unidos consiste hoy en una evaluación de diversos factores relevantes y la literatura especializada se ha enfocado en el análisis del peso relativo que estos factores deben tener ${ }^{13}$.

Es claro que el tema de la autoejecutabilidad se ha complejizado. La Cláusula de la Supremacía surgió como respuesta a un problema específico: el rechazo de los Estados de la Confederación a cumplir con los tratados negociados por el poder federal ${ }^{14}$. Sin embargo, en la medida que cada vez existen más tratados y en que estos imponen obligaciones al Estado dentro de su esfera interna -en las relaciones jurídicas con personas que se ubican dentro de su propio territorio- entonces la autoejecutabilidad se convierte en una forma de implementar normas exógenas, que tienen su génesis fuera de la comunidad política respectiva, dentro del sistema jurídico nacional, desafiando la forma en que la Constitución ha distribuido el poder.

La relación entre el derecho internacional y el derecho interno de los Estados se hace particularmente difícil en las democracias deliberativas ${ }^{15}$. Como lo ha expuesto Rodrigo Correa, en las democracias constitucionales existe una tensión entre el principio de la soberanía popular y el derecho internacional, porque bajo el primer principio se justificaría requerir que los tratados, al igual que las leyes, cumplan con los requisitos procedimentales democráticos del derecho interno16. Como eso no es posible, hay que asumir la existencia de la tensión entre los principios democráticos y la incorporación de tratados internacionales en el derecho nacional. La generación de una doctrina sobre autoejecutabilidad es simplemente el resultado de la constatación de la tensión entre el derecho internacional y la democracia. Se trata, en definitiva, de un problema político. Por ello, la decisión sobre el efecto directo de las normas internacionales es una cuestión entregada al derecho interno de cada estado y no es algo regulado por el derecho internacional:

${ }^{8}$ KAISER, Karen (2013), "Treaties, Direct Applicability". En: WOLFRUM, Rüdiger (Ed.), Max Planck Encyclopedia of Public International Law. Disponible en: http://opil.ouplaw.com/view/10.1093/law:epil/9780199231690/law-9780199231690-e1468 [fecha de visita 28 de octubre de 2018], pfo. 4.

9La Cláusula Sexta, párrafo 2, dispone lo siguiente: "This Constitution, and the Laws of the United States which shall be made in Pursuance thereof; and all Treaties made, or which shall be made, under the Authority of the United States, shall be the supreme Law of the Land; and the Judges in every State shall be bound thereby, any Thing in the Constitution or Laws of any State to the Contrary notwithstanding."

10VÁSQUEZ (1995) 699.

${ }^{11}$ Foster v. Neilson, 27 U.S. (2 Pet) 253 (1829)

${ }^{12}$ La evolución se puede consultar en VÁSQUEZ, Carlos Manuel (2008), "Treaties as Law of the Land: The Supremacy Clause and the Judicial Enforcement of Treaties". Harvard Law Review, vol. 122, pp. 599-695.

13VÁSQUEZ (2008) 629-667. El análisis de los criterios utilizados en Estados Unidos para determinar la autoejecutabilidad de un tratado también puede consultarse en FUENTES (2014) 617 y PÉREZ (2015) 36-40.

${ }^{14}$ SLOSS, David L. (2016), The Death of Treaty Supremacy: An Invisible Constitutional Change. Oxford: Oxford University Press, pp. 472, pp. 24-26. Véase, también, pp. 1-28.

${ }^{15} \mathrm{KAHN}$, Paul W. (2011) "El derecho internacional y la comunidad". En D'ALESSIO, Andrés (Ed.) Estado de derecho y democracia: un debate acerca del rule of law. Buenos Aires: Editores del Puerto, pp. 267-280.

${ }^{16}$ CORREA, Rodrigo (2008) International Law: The View from the Republic (Tesis de doctorado no publicada). New Haven: Yale University, p. 1. En sus conclusiones Correa dice: "This explains the complexity of the relationships between constitutional democracies and international law. It is not that popular sovereignty excludes the validity of any law that it is not its own creature-and international law is certainly not the creature of the people-but rather that international law does not appear to be vested with legitimacy comparable to that of democratic law." (Capítulo 7). 